\title{
The information content in a volatility index for Spain
}

\author{
Maria T. Gonzalez-Perez • Alfonso Novales
}

Received: 23 January 2009 / Accepted: 1 September 2010 / Published online: 1 October 2010 (C) The Author(s) 2010. This article is published with open access at Springerlink.com

\begin{abstract}
A model-free methodology is used for the first time to estimate a daily volatility index (VIBEX-NEW) for the Spanish financial market. We use a public data set of daily option prices to compute this index and show that daily changes in VIBEXNEW display a negative, tight contemporaneous relationship with IBEX daily returns, contrary to other common volatility indicators, as an implied volatility indicator or a $\operatorname{GARCH}(1,1)$ conditional volatility model. This relationship is approximately symmetric to the sign on VIBEX-NEW changes and asymmetric to the IBEX-35 returns sign, which make it clearly a suitable volatility index for the Spanish stock market. We also examine the relationship between current VIBEX-NEW and future IBEX-35 volatility. Our results suggest that VIBEX-NEW can be used to produce IBEX-35 volatility forecasts at least as good as historical and conditional volatility measures. A feasible volatility correction methodology is proposed to achieve it.
\end{abstract}

Keywords Model-based volatility index - Model-free volatility index · Risk · Leverage effect $\cdot$ Forecasting volatility

JEL Classification $\quad \mathrm{C} 53 \cdot \mathrm{G} 13 \cdot \mathrm{G} 15$

\section{Introduction}

In 1993, the CBOE (Chicago Board Option Exchange) first published the VIX index with the intention of providing information on the perception of risk in the US stock

M. T. Gonzalez-Perez ( $\square)$

Finance Department, Northwestern University, Evanston, USA

e-mail: m-gonzalezperez@kellogg.northwestern.edu

A. Novales

Departamento de Fundamentos del Analisis Economico II,

Universidad Complutense de Madrid, Madrid, Spain

e-mail: anovales@ccee.ucm.es 
market. Since then, other volatility indices have been officially created in different international markets with the same purpose. They have quickly become standard tools for risk management, increasingly being used as underlying assets for some derivative products.

Volatility indices are computed from the information quoted on a derivative market, where investors buy and sell contracts according to their perception of current and future market risk. The two main methodologies used to estimate volatility indices differ in the options considered in the process, presumably because of a different interpretation of the way in which option prices incorporate the market perception of risk. The older methodology uses ATM short-term call and put implied volatilities (see Whaley 2000) to compute the volatility index, while a more recent methodology is based on prices for near to maturity ATM and OTM call and put options (see Deutsche Borse 2007). The first methodology is usually referred to as a model-based methodology because an option valuation model is needed to compute the volatility index, while the second one is a model-free methodology that does not need such a valuation model. As of today, a public and official volatility index does not exist for Spanish financial markets, and our intention in this article is to propose and analyze a candidate for an official volatility index in Spanish financial markets.

It is very common in the literature to compute daily volatility indices from closing option prices. Nevertheless, the Spanish option market on IBEX-35 is low on liquidity, and settlement option prices provided by the Clearing House could be far from market prices. ${ }^{1}$ On the other hand, their use could limit the information included in a volatility index, since the index is not based on the information reported in the market, but from a survey. Intraday quotes are better to use in computing the Spanish volatility index, but it is currently difficult to obtain intraday information on the Spanish option market in a manageable format over the whole sample, so we proceed as in most of the literature, and use option closing data to estimate the Spanish volatility index.

Model-free methodology to compute the volatility index is based on the notion of Model Free Implied Variance (MFIV) by Britten-Jones and Neuberger (2000). This methodology is simpler than the model-based and makes possible to value derivatives on this index. From an empirical point of view, since the model-free methodology uses a wider range of strikes than model-based to compute the index, this is better to compute a intraday volatility index in less liquid option markets. ${ }^{2}$ In this article a model-free methodology is for the first time used to compute a Spanish volatility index.

This paper intends (i) to propose a model-free volatility index for the Spanish option market and (ii) to examine the information content in such volatility index from two

\footnotetext{
1 Settlement prices are set by MEFF RV after the closing market time from a survey that asks for information on volatility across maturities. A term structure for volatility, as well as a model for the volatility smile are used to infer implied volatilities for individual options.

2 Even more important, by using a wider set of options, a model-free methodology enables the volatility index to be computed essentially every day, contrary to what happens with a volatility index based on an option valuation model.
} 
points of view, related to the volatility index definition: analyzing the VIBEX-NEW and current IBEX-35 returns relationship to characterize the market leverage effect, and examine the relationship between VIBEX-NEW and the measure it intends to approximate, the future IBEX-35 volatility, which is very useful in the study of the Spanish volatility risk premium.

A volatility index can only be considered an official volatility index if it provides useful information about current perception of risk in the Spanish financial market. Therefore, we first explore the relationship between changes in the level of volatility index and market returns, to decide whether it is significantly negative. Next, we reach a conclusion on the symmetry in the above-mentioned relationship relative to the volatility change sign and to the stock index return sign. Skiadopoulos (2004), Fleming et al. (1995) and Giot (2005), among others, report that the relationship between changes in official volatility indices and the indices returns is negative and asymmetric. We conclude that such relationship is symmetric relative to the daily VIBEXNEW change sign, but asymmetric relative to the daily IBEX-35 return sign (similar to Whaley 2009).

In the second exercise we explore the forecasting ability of the VIBEX-NEW, even though volatility indices have not been proposed to forecast future volatility in the stock index. To this respect the literature reports mixed results. Blair et al. (2001), Engle and Gallo (2007), Giot and Laurent (2007), Fleming et al. (1995), and Corrado and Miller (2005), among others, conclude in favor of the forecasting ability of US volatility indices, whereas Becker et al. (2007) and Bali and Weinbaum (2007) conclude that the VIX index does not add information to model-based volatility forecasts. The results of this exercise show that VIBEXNEW demonstrates a forecasting ability similar to that of historical or implied volatility indicators, after we apply a methodology to reduce, but no remove, the forecasting bias. We also report that the forecasting precision in all volatility variables as unbiased forecasters is not very high. We consider this result is crucial to analyze the size and evolution of the volatility risk premium in Spanish Financial Markets.

The paper is organized as follows: Section 2 summarizes the model-free and model-based methodologies to estimate Spanish volatility indices. Section 3 analyzes how the volatility index is related to IBEX-35 returns, while Sect. 4 studies the ability of the volatility index to anticipate future volatility in the stock market index. The article ends with conclusions and questions that remain open for further research.

\section{The Spanish volatility index}

We compute two volatility indices for Spanish Financial Market, VIBEX-NEW and VIBEX. VIBEX is a model-based index, like the US VXO, and VIBEX-NEW is a model-free index, like the new US VIX. In this section we describe the data we use to compute these two indices, the steps we follow to compute them, and main differences and similarities between these and other international volatility indices. 


\subsection{Data}

Daily settlement ${ }^{3}$ prices for futures on IBEX-35, and option prices on IBEX-35, from January 1997 to March 2007, were provided by MEFF RV (http://www.meff. com) into the following files: hp97000i.zip, hp98000i.zip, hp99000i.zip, hp00000i.zip, hp011q0i.zip, hp01000i.zip, hp021s0i.zip, hp02000i.zip, hp0301s0i.zip, hp03000i. zip, hp041s0i.zip, hp04000i.zip, hp051s0i.zip, hp05000i.zip, HP06FIE1.zip, HP06 FIE2.zip, HP0701FIE.zip, HP0702FIE.zip and HP0703FIE.zip. Daily closing quotes for IBEX35 are provided by Sociedad de Bolsas (http://www.sbolsas.com) for the same period of time. Finally, the risk-free interest rate is the daily 1-month MIBOR, which is obtained from the EcoWin platform (Reuters).

\subsection{Model-based volatility index: VIBEX}

Model-based methodology to compute the volatility index assumes that the Black and Scholes implied volatility, from a synthetic ATM option on the stock index, with one-month to maturity, informs about volatility expected in the market one month in advance. Whaley (2000) develops this idea and proposes estimating such a volatility index from eight ATM call and put implied volatilities, with the two closest maturities to 30 calendar days. This methodology is called model-based because of the option valuation model we use to compute the volatility index.

In this article we set two volatility indices as reference to the US and an European model-based volatility indices: the US VXO and the German VDAX model-based volatility indices, respectively. VXO and VDAX are computed according to the methodology described in Whaley (2000), but the Deutsche Borse (DB, the German Stock Market) introduces some small changes on this (see Table 1). First, DAX options are issued on the DAX future instead of on the stock index (as is VXO) so DB uses Black (1976) model to infer the implied volatility while the CBOE uses Black and Scholes (1973). Another difference is that DB transforms the option and forward prices in the process to induce symmetry between same class of call and put options, before inverting the valuation model and computing the implied volatility. CBOE does not do this transformation and assumes that such asymmetry always holds. Finally, VDAX is referred to a different future period of time, the next 45 calendar days, while VXO is referred to the following 30 calendar days. This implies the use of different option maturities in computing both indices.

In this article we propose to estimate a model-based volatility index for Spain to inform on the volatility expected in the following 30 calendar days. This index will be based in Whaley (2000) methodology with the only difference that we will use the Black (1976) model to estimate the implied volatility, instead of the Black and Scholes (1973), because IBEX options are issued on IBEX-35 future.

CBOE and DB impose some filters to the data set in order to avoid the use of bad data in computing the volatility index. We accommodate such filters to the

\footnotetext{
3 We use settlement prices instead of closing option quote prices, because the first avoid asynchrony problems in option quotes due to low-traded contracts.
} 
Spanish Market characteristics and require non-zero mid bid-ask settlement option prices to compute the volatility index. This filter can strongly reduce the number of Near-the-money option quotes, in a way that the VIBEX cannot be computed in around $7-8 \%$ the trading days, depending on the year. This is similar to the DB filter which computes VDAX and, although CBOE does not specify whether OEX options with zero bid and/or zero ask are considered to compute the VXO, we assume that this never happens for settlement S\&P100 option prices. Due to the strong reduction in ATM options when we apply such a filter we let options closer to the underlying quote until $\operatorname{NTM}(5 \%)$ to compute the index, and omit those with an associated volume equal to zero in order to avoid non-traded quotes in volatility index computation. $^{4}$

Giner and Morini (2004) ${ }^{5}$ compute a model-based volatility index for the Spanish financial market, but their volatility index (also called VIBEX) is computed from official implied volatilities provided by MEFF for each contract, just after the closing time, and not from option prices. Our belief is that a volatility index should be able to be reproduced and non-zero official implied volatilities are sometimes recorded jointly with a zero settlement price in our data set, which has no economical meaning. Therefore, we compute the model-based volatility index from option prices publicly provided by MEFF RV.

We use two different maturities to compute the volatility index but only one maturity interest rate: 1-month MIBOR. ATM implied volatilities seem not to be sensitive to the maturity of MIBOR, when it is 1 or 2 month, so we simplify the exercise by using always the 1-month MIBOR. To this respect, DB uses a linear interpolation of EONIA 1 day and EURIBOR 1 or 2 months to compute the VDAX, and CBOE uses a continuous yield on T-bills whose maturity most closely matches the expiration time. These similarities and differences are summarized in Table 1. Our assumption is that the VIBEX level will not change significantly with a higher maturity interest rates.

We proceed to briefly describe the VIBEX calculus. For each of the two maturities $T_{1}$ and $T_{2}$, the ones immediately before and after the forecast horizon $\mathrm{H}$ (22 trading days or 30 calendar days), we select four NTM (5\%) non-zero priced options, two call and two put options with strike prices close to the ATM for both sides. We call $K_{d 1}$ and $K_{u 1}$ to the strike prices below and higher the ATM strike for the first maturity, and $K_{d 2}$ and $K_{u 2}$ are strike prices below and higher the ATM strike for the second maturity. ATM strike price is computed as $K / F_{T_{1}}$ for the first maturity, and as $K / F_{T_{2}}$ for the second maturity, where $F_{T}$ is the settlement price for the future on IBEX-35 and maturity date $T{ }^{6}$ Next, we use Black's (1976) valuation model to estimate an implied volatility (IV) from each quote (see second column in Table 2). These will be aggregated according to (1) in order to obtain an implied volatility for each strike price and maturity.

\footnotetext{
4 As Noh et al. (1994) suggest, quotes related to trades have more information on volatility market expectations.

5 Working paper (Departamento de Economia Financiera y Contabilidad, Universidad de La Laguna).

6 Notice that $F_{T_{1}}$ and $F_{T_{2}}$ can be different, so $K_{d 1}\left(K_{d 2}\right)$ can be different to $K_{d 2}\left(K_{u 2}\right)$.
} 
Table 1 Computational criteria in following model-based volatility indices: VDAX, VXO and VIBEX

\begin{tabular}{|c|c|c|c|}
\hline & VDAX & $\mathrm{VXO}$ & VIBEX \\
\hline Horizon $^{\mathrm{a}}$ & 45 & 30 & 30 \\
\hline Underlying & DAX forward price & S\&P 100 & Futures on IBEX-35 \\
\hline $\mathrm{OVM}^{\mathrm{b}}$ & Black (1976) & Black and Scholes (1973) & Black (1976) \\
\hline Option price & Mid bid-ask point & Mid bid-ask point & $\begin{array}{l}\text { Settlement price } \approx \text { Mid } \\
\text { bid-ask point }\end{array}$ \\
\hline Risk-free $r$ & $\begin{array}{l}\text { Linear interpolation: } \\
\text { EONIA (1 day), Euribor }\end{array}$ & $\begin{array}{l}\text { Continuous yield on T-bill } \\
\text { whose maturity most } \\
\text { closely matches the } \\
\text { expiration time }\end{array}$ & MIBOR 1 month \\
\hline Specific filters & $\begin{array}{l}\text { ATM call and put options } \\
\text { with two-side market }{ }^{\mathrm{d}} \\
\text { and non-zero priced with } \\
\text { official maximum spread }\end{array}$ & ATM call and put options & $\begin{array}{l}\text { Among the NTM }(5 \%) \text { call } \\
\text { and put options, those } \\
\text { closest to ATM } \\
\text { associated to non-zero } \\
\text { official implied volatility } \\
\text { or zero volume traded at } \\
\text { the closing time, and a } \\
\text { non-zero settlement } \\
\text { price }\end{array}$ \\
\hline
\end{tabular}

${ }^{a}$ Calendar days

b Option valuation model

${ }^{c}$ When bid and ask are provided, the settlement price is equal to the mid bid-ask point. Nevertheless, some non-zero settlement prices are provided with zero bid and/or ask prices

$\mathrm{d}$ Options with non-zero bid and ask prices

Table 2 Quotes and implied volatilities used in computing VIBEX

\begin{tabular}{llll}
\hline & Quotes & & Implied volatilities \\
\hline First maturity: & $C\left(T_{1}, K_{d 1}\right)$ & $\rightarrow$ & $I V_{C\left(T_{1}, K_{d 1}\right)}$ \\
& $C\left(T_{1}, K_{u 1}\right)$ & $\rightarrow$ & $I V_{C\left(T_{1}, K_{u 1}\right)}$ \\
& $P\left(T_{1}, K_{d 1}\right)$ & $\rightarrow$ & $I V_{P\left(T_{1}, K_{d 1}\right)}$ \\
& $P\left(T_{1}, K_{u 1}\right)$ & $\rightarrow$ & $I V_{P\left(T_{1}, K_{u 1}\right)}$ \\
Second maturity: & $C\left(T_{2}, K_{d 2}\right)$ & $\rightarrow$ & $I V_{C\left(T_{2}, K_{d 2}\right)}$ \\
& $C\left(T_{2}, K_{u 2}\right)$ & $\rightarrow$ & $I V_{C\left(T_{2}, K_{u 2}\right)}$ \\
& $P\left(T_{2}, K_{d 2}\right)$ & $\rightarrow$ & $I V_{P\left(T_{2}, K_{d 2}\right)}$ \\
& $P\left(T_{2}, K_{u 2}\right)$ & $\rightarrow$ & $I V_{P\left(T_{2}, K_{u 2}\right)}$ \\
\hline
\end{tabular}

$$
\begin{aligned}
& I V_{T_{1}, K_{d 1}}=\frac{I V_{C\left(T_{1}, K_{d 1}\right)}+I V_{P\left(T_{1}, K_{d 1}\right)}}{2}, \quad I V_{T_{1}, K_{u 1}}=\frac{I V_{C\left(T_{1}, K_{u 1}\right)}+I V_{P\left(T_{1}, K_{u 1}\right)}}{2} \\
& I V_{T_{2}, K_{d 1}}=\frac{I V_{C\left(T_{2}, K_{d 1}\right)}+I V_{P\left(T_{2}, K_{d 1}\right)}}{2}, \quad I V_{T_{2}, K_{u 1}}=\frac{I V_{C\left(T_{2}, K_{u 1}\right)}+I V_{P\left(T_{2}, K_{u 1}\right)}}{2}
\end{aligned}
$$

Volatilities in (1) are secondly aggregated according to expressions in (2) to have a volatility measure for each maturity. 


$$
\begin{aligned}
& I V_{T_{1}}=I V_{T_{1}, K_{d 1}} \frac{K_{u 1}-F_{T_{1}}}{K_{u 1}-K_{d 1}}+I V_{T_{1}, K_{u 1}} \frac{F_{T_{1}}-K_{d 1}}{K_{u 1}-K_{d 1}} \\
& I V_{T_{2}}=I V_{T_{2}, K_{d 2}} \frac{K_{u 2}-F_{T_{2}}}{K_{u 2}-K_{d 2}}+I V_{T_{2}, K_{u 2}} \frac{F_{T_{2}}-K_{d 2}}{K_{u 2}-K_{d 2}}
\end{aligned}
$$

Finally, VIBEX is obtained by aggregating previous volatility measures according to expression (3), where $\mathrm{H}$ is the volatility index forecast ${ }^{7}$ horizon (in our case, 30 calendar days). We multiply by 100 to obtain VIBEX as a percentage.

$$
V I B E X=100 \cdot\left(I V_{T_{1}} \frac{T_{2}-H}{T_{2}-T_{1}}+I V_{T_{2}} \frac{H-T_{1}}{T_{2}-T_{1}}\right)
$$

\subsection{Model-free volatility index: VIBEX-NEW}

According to the seminal work by Britten-Jones and Neuberger (2000), a model-free volatility index $V$ intends to reflect the expected integral of future variances between now and a future date, over a Q-measure $\left(V=E_{Q}\left[\int_{0}^{T} \sigma_{t}^{2}\right]\right)$. Based on this idea, and on the results reported by Demeterfi et al. (1999), CBOE proposes a methodology to compute the US model-free volatility index, called VIX. In fact, CBOE adapted this theoretical framework for the use of discrete time series and available underlying prices, see Jiang and Tian (2007). This methodology avoids the use of an option valuation model whose assumptions do not hold in practice, and offers enough simplicity in the calculus to make possible the valuation of derivatives on a volatility index, which is very difficult when the volatility index is a model-based index.

Even $\mathrm{CBOE}$ and DB model-free methodologies share the same origin, there are some differences between them (summarized in Table 3). The Spanish volatility index VIBEX-NEW is based on the steps described by DB due to the scarce of information in the CBOE's document to compute a model-free volatility index, compared to the information content in Deutsche Borse's document. Both methodologies differ in filters to the data set although both intend to remove bad option prices. Filters we apply have the same purpose and are adapted to our data set characteristics: we only consider options with a price higher or equal to five IBEX points, and three or more calendar days to maturity. The first filter prevents to consider very OTM options that some times are bad valuated and the second filter removes possible bad prices due to the proximity in maturity time.

We describe briefly the process to compute VIBEX-NEW. First step is to select two maturities $T_{1}$ and $T_{2}$, previous and subsequent to the 30 calendar days (22 trading days). Then, we calculate associated ATM strike prices ${ }^{8}$ for each of the two maturities. We call $K_{0, T_{1}}$ and $K_{0, T_{2}}$ to the ATM strike price for the first and second

\footnotetext{
7 We italicize forecast because a volatility index intends to measure the expected volatility and no the future volatility.

8 It is important to notice that these ATM strike prices are obtained as those prices for which the call and put premium are closer to each other for each maturity. Notice that, since the strike with minimum bid-ask spread could be different for each maturity, the ATM strike price for each maturity $\left(K_{0, T_{1}}\right.$ and $\left.K_{0, T_{2}}\right)$ may be different.
} 
Table 3 Computational criteria in following model free volatility indices: VDAX-NEW, VIX and VIBEXNEW

\begin{tabular}{|c|c|c|c|}
\hline & VDAX-NEW & VIX & VIBEX-NEW \\
\hline Horizon $^{\mathrm{a}}$ & 30 & 30 & 30 \\
\hline Underlying & $\begin{array}{l}\text { ATM and OTM options on } \\
\text { DAX futures }\end{array}$ & $\begin{array}{l}\text { ATM and OTM S\&P500 } \\
\text { options }\end{array}$ & $\begin{array}{l}\text { ATM and OTM options on } \\
\text { IBEX-35 futures }\end{array}$ \\
\hline Option price & Mid bid-ask point & Mid bid-ask point & $\begin{array}{l}\text { Settlement price } \approx \mathrm{Mid} \\
\text { bid-ask point }{ }^{\mathrm{b}}\end{array}$ \\
\hline Risk-free r & $\begin{array}{l}\text { Linear interpolation: EO- } \\
\text { NIA (1 day), Euribor }\end{array}$ & $\begin{array}{l}\text { The bond-equivalent yield } \\
\text { of the U.S. T-bill matur- } \\
\text { ing closest to the expi- } \\
\text { ration dates of relevant } \\
\text { SPX options }\end{array}$ & MIBOR 1 month \\
\hline Specific filters & $\begin{array}{l}\text { Remove one-sided }{ }^{\mathrm{c}} \text { and } \\
\text { zero option prices, as } \\
\text { well options with spread } \\
\text { out of the maximum offi- } \\
\text { cial spread for Eurex. } \\
\text { Only options with mini- } \\
\text { mal time to maturity of } \\
\text { two days } \mathrm{d}\end{array}$ & $\begin{array}{l}\text { Remove zero option prices } \\
\text { and OTM option prices } \\
\text { far away from two con- } \\
\text { secutive zero bid prices. } \\
\text { Only options with mini- } \\
\text { mal time to maturity of } \\
\text { five trading days }\end{array}$ & $\begin{array}{l}\text { Remove zero option set- } \\
\text { tlement prices. Only } \\
\text { options with minimal } \\
\text { time to maturity of three } \\
\text { calendar days }\end{array}$ \\
\hline
\end{tabular}

${ }^{a}$ Calendar days

${ }^{\mathrm{b}}$ When bid and ask are provided, the settlement price is equal to the mid bid-ask point. Nevertheless, some non-zero settlement prices are provided with zero bid and/or ask prices

c Options with zero bid or zero ask

d It is not said whether these are calendar days or not

maturity respectively, and we compute them according to expressions in (4).

$$
\begin{aligned}
& K_{0, T_{1}}=K / \min \left|C\left(T_{1}, K\right)-P\left(T_{1}, K\right)\right|, \forall \text { available } K \\
& K_{0, T_{2}}=K / \min \left|C\left(T_{2}, K\right)-P\left(T_{2}, K\right)\right|, \forall \text { available } K
\end{aligned}
$$

Next, we use the function $M(T, K)$ to make a correspondence between the moneyness of an option and its price for each maturity, with the intention of determining option prices included in VIBEX-NEW calculus. Therefore, $M(T, K)$ is a vector of option prices for each maturity. We use the subindex $j$ for the $\mathrm{j}-t h$ OTM option and the subindex $i$ for the maturity (in our case $i=1,2$ ). See expression (5).

$$
M\left(T_{i}, K_{j}\right)= \begin{cases}P\left(T_{i}, K_{j}\right) & \text { if } K_{j}<K_{0, T_{i}} \\ \frac{P\left(T_{i}, K_{j}\right)+C\left(T_{i}, K_{j}\right)}{2} & \text { if } K_{j}=K_{0, T_{i}} \\ C\left(T_{i}, K_{j}\right) & \text { if } K_{j}>K_{0, T_{i}}\end{cases}
$$

Following this, we weight option prices. The weight depends on the distance between the previous and posterior OTM strike prices $\left(\nabla K_{j}=\frac{K_{j-1}+K_{j+1}}{2}\right)$ and on the appropriate discount factor $\left(R_{1}\right.$ and $\left.\left.R_{2}\right)\right)$. The discounts factor $R_{i}$ in (6) is determined according to $R_{i}=e^{r_{i} \cdot T_{i}}$, where $r_{i}$ is the risk-free interest rate to expiration 
for the $\mathrm{i}-t$ th option on IBEX-35 future (MIBOR 1 month). We estimate the variance for each maturity, $\sigma_{i}^{2}$, by correcting the previous weight sum of option prices by an expression depending on the distance between the forward price and the ATM strike prices (see expression (6)). Forward index prices $F_{i}(i=1,2)$ are computed according to $(7)$.

$$
\begin{gathered}
\sigma_{i}^{2}=\frac{2}{T_{i}} \cdot \sum_{j} \underbrace{\frac{\Delta K_{j, T_{i}}}{K_{j, T_{i}}^{2}} \cdot R_{i}}_{\text {weight }} \cdot \underbrace{M\left(T_{i}, K_{j}\right)}_{\text {option prices }}-\frac{1}{T_{i}}\left(\frac{F_{i}}{K_{0, T_{i}}}-1\right)^{2}, \quad \text { for } i=1,2 \\
F_{i}=K_{0, T_{i}}+e^{R_{i} \cdot T_{i}}\left(C\left(T_{i}, K_{0, T_{i}}\right)-P\left(T_{i}, K_{0, T_{i}}\right)\right), \quad \text { for } i=1,2
\end{gathered}
$$

Finally, VIBEX-NEW is generated as a linear interpolation of two $\sigma_{i}^{2}$ variances (see (8)). In the expression, $N_{T_{i}}$ is the number of minutes to settlement of near-term $(\mathrm{i}=1)$ and next-term ( $\mathrm{i}=2$ ) options. $N_{T}$ is the number of minutes in 30 calendar days and $N_{365}$ is the number of minutes in 365 days. Finally, $T_{1}$ and $T_{2}$ are the annualized number to minutes until each of the expirations. This is the CBOE's definition for these variables, but Deutsche Borse defines $N_{T}, N_{1}, N_{2}, N_{365}, T_{1}$ and $T_{2}$ in number of seconds, instead in number of minutes, with the intention to improve the accuracy in measuring these variables within the trading day. Nevertheless, since we always compute the VIBEX-NEW at the closing time, measure time to expiration in number of minutes or number of seconds induce the same accurate in computing VIBEX-NEW so this decision is irrelevant for daily volatility index calculus.

VIBEX-NEW $=100 \cdot \sqrt{\left[T_{1} \cdot \sigma_{1}^{2} \cdot\left(\frac{N_{T_{2}}-N_{T}}{N_{T_{2}}-N_{T_{1}}}\right)+T_{2} \cdot \sigma_{2}^{2} \cdot\left(\frac{N_{T}-N_{1}}{N_{T_{2}}-N_{T_{1}}}\right)\right] \cdot \frac{N_{365}}{N_{T}}}$

\subsection{Volatility indices. Data description}

Differences in OTM call (put) and ATM call (put) prices explain the different levels in model-free and model-based volatility indices. This is a stylized fact reported by Andersen and Bondarenko (2007) ${ }^{9}$ for VIX, that also holds for VIBEX and VIBEXNEW. Table 4 shows that the (model-based) VIBEX mean is smaller than the (modelfree) VIBEX-NEW mean each year and over the entire sample. This difference varies over the sample, reflecting the evolution of market perspectives. Figure 1 shows the ratio $\frac{\text { VIBEX-NEW }}{\text { VIBEX }}$, which is higher or equal to one in $93.8 \%$ of the trading days, and fewer to 1 only in $6.2 \%$ of trading days due to the scarce of reliable filtered data to compute VIBEX in some days. In fact, VIBEX cannot be computed in $8 \%$ of trading days over the sample because no ATM (IBEX-35) option price holds the filters. In contrast, VIBEX-NEW can be computed over all trading days.

\footnotetext{
$\overline{9}$ NBER Working Paper Series (13449).
} 
Table 4 Descriptive statistics: VIBEX-NEW and VIBEX

\begin{tabular}{|c|c|c|c|c|}
\hline & \multicolumn{2}{|l|}{ Mean } & \multicolumn{2}{|l|}{ Median } \\
\hline & VIBEX-NEW & VIBEX & VIBEX-NEW & VIBEX \\
\hline 1997 & 25.40 & 25.13 & 24.56 & 24.32 \\
\hline 1998 & 35.27 & 33.58 & 32.52 & 31.04 \\
\hline 1999 & 27.84 & 26.22 & 25.88 & 24.78 \\
\hline 2000 & 26.13 & 25.41 & 26.63 & 26.05 \\
\hline 2001 & 27.07 & 26.53 & 25.36 & 25.04 \\
\hline 2002 & 32.65 & 31.85 & 30.79 & 29.80 \\
\hline 2003 & 24.22 & 23.35 & 22.36 & 21.55 \\
\hline 2004 & 15.28 & 14.77 & 14.91 & 14.41 \\
\hline 2005 & 11.83 & 11.41 & 11.63 & 11.14 \\
\hline 2006 & 13.74 & 13.21 & 12.87 & 12.41 \\
\hline $2007 *$ & 15.83 & 14.73 & 14.82 & 14.01 \\
\hline \multirow[t]{3}{*}{ All sample } & 23.68 & 22.90 & 23.02 & 22.42 \\
\hline & \multicolumn{2}{|l|}{ Skewness } & \multicolumn{2}{|l|}{ Kurtosis } \\
\hline & VIBEX-NEW & VIBEX & VIBEX-NEW & VIBEX \\
\hline 1997 & 1.06 & 1.22 & 1.42 & 2.36 \\
\hline 1998 & 1.26 & 1.34 & 0.97 & 1.21 \\
\hline 1999 & 1.48 & 1.25 & 1.78 & 1.08 \\
\hline 2000 & 0.00 & -0.08 & -0.90 & -0.91 \\
\hline 2001 & 1.09 & 1.16 & 0.75 & 0.93 \\
\hline 2002 & 0.46 & 0.42 & -1.01 & -1.06 \\
\hline 2003 & 0.58 & 0.53 & -0.95 & -0.98 \\
\hline 2004 & 0.68 & 0.67 & 0.01 & -0.05 \\
\hline 2005 & 0.66 & 0.65 & -0.01 & -0.11 \\
\hline 2006 & 1.51 & 1.52 & 1.95 & 2.12 \\
\hline $2007 *$ & 0.90 & 1.16 & 0.00 & 0.87 \\
\hline All sample & 0.81 & 0.80 & 0.66 & 0.70 \\
\hline
\end{tabular}

* Only until the end of March 2007

Since VIBEX-NEW incorporates the OTM put options (insurance against drops in the stock index) and OTM call options (indicator of enthusiasm in markets) we consider that this volatility index is a better candidate to inform about Spanish Investor Fear Gauge than the model-based VIBEX, and we propose it a potential Spanish official model-free volatility index. In following sections we proceed to examine the informational content in VIBEX-NEW to evaluate its possible use as an official volatility index in the Spanish financial market. We study the information content in such volatility index from two points of view, related to a volatility index definition: we examine the relationship between contemporaneous VIBEX-NEW and IBEX-35 

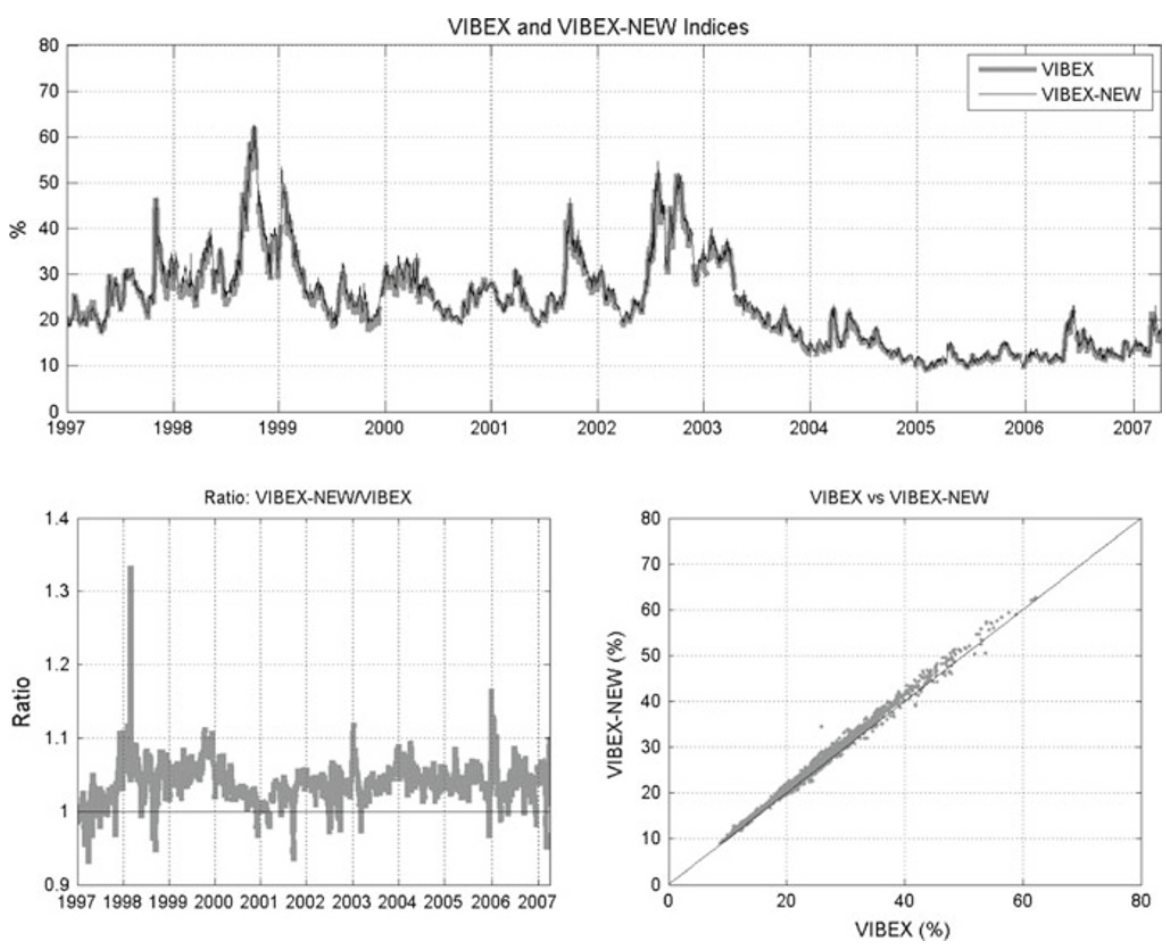

Fig. 1 VIBEX and VIBEX-NEW. Daily indices 1997-2007 (\%)

returns to characterize the market leverage effect, and between VIBEX-NEW and the measure it intends to approximate (anticipate), the future IBEX-35 volatility.

\section{The VIBEX-NEW as an indicator of current risk}

In this section we examine whether the VIBEX-NEW is a gauge of Spanish investor fears. If so, VIBEX-NEW could be considered an official volatility index for the Spanish financial markets.

According to Whaley (2000), an index (e.g. VIBEX-NEW) is an investor fear gauge if changes in it maintain a significant and negative contemporaneous relationship with stock market returns (e.g. IBEX-35). The contemporaneous relationship between the Spanish volatility index and the IBEX-35 returns is analyzed deeply in this section, where we analyze not only the sign, but also the symmetry in the relationship between VIBEX-NEW and IBEX-35 daily movements. Two approximations (graphical and statistical analysis) will allow us to illustrate this relationship.

\subsection{The return-volatility relationship: graphical analysis}

Figure 2 compares daily IBEX35 prices and the VIBEX-NEW for the entire sample. As we can see, the IBEX35 index started in 1997 at 5000 and ended the sample period 


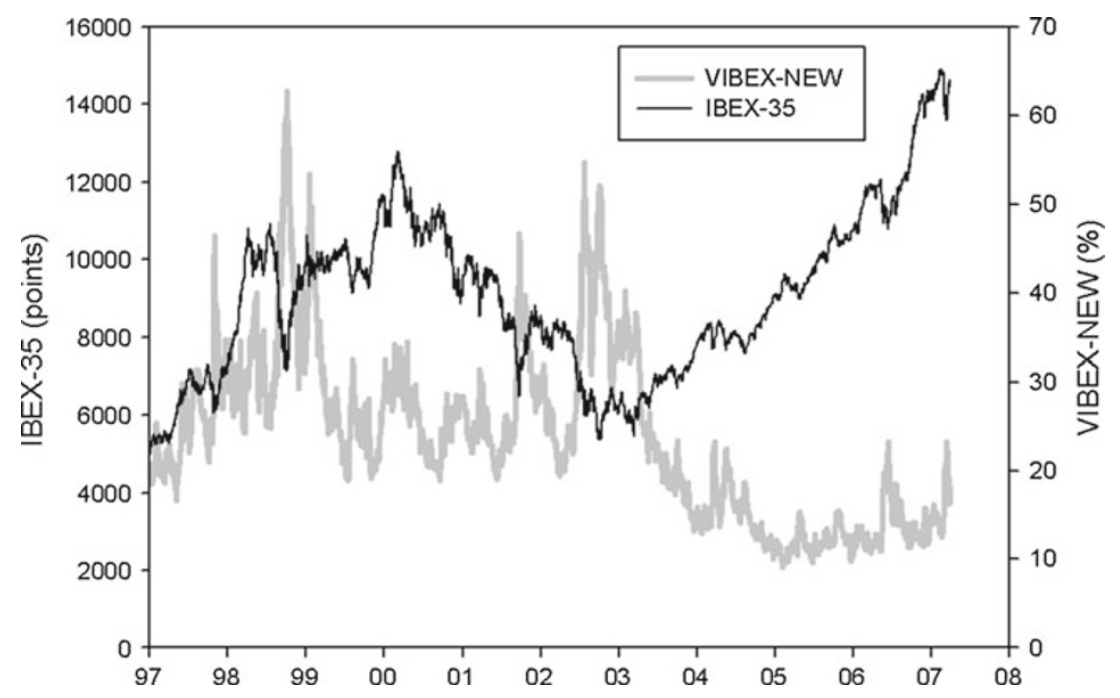

Fig. 2 VIBEX-NEW (\%) versus IBEX-35. Daily data

(March 2007) at 15000, which suggests strong changes in IBEX-35 during the considered sample. Indeed, volatility increased from January 1997 to August 1998, when the market was on a positive trend. In that period, volatility doubled over the space of 5 days at the end of October 1997, when the market underwent a moderate fall. Volatility again doubled in August 1998 because of the Black Monday episode. There was again a volatility spike at the beginning of January 1999, when the market fell by only about $4 \%$. Volatility remained relatively stable, in the $20-30 \%$ range up to September 2001, in spite of the fact that the market index was falling from a historical maximum of 12817 on March 3rd, 2000. This was a total fall of $-35.3 \%$ in the index with no evident reflection in the volatility index. A further sudden fall of $-20.0 \%$ in the IBEX in the first part of September 2001 implied a drastic leap in volatility, from 25 to $47 \%$. Volatility quickly returned to its previous level as the market also recovered. With the exception of the September 2001 observation, there does not seem to be a close relationship between the two indices.

A new negative period occurred between mid April and August 2002, with a fall of $-28.7 \%$ in IBEX, and VIBEX-NEW rising drastically from 20 to 55\%, while experiencing wide swings. This episode is interesting because we see the volatility index underwent a very sharp increase as soon as the market index started experiencing a noticeable fall. However, VIBEX-NEW started a downward path to recover a level below $20 \%$ well before the IBEX35 started its own recovery. In this period, as well as in the rest of the sample, the volatility index experienced wide oscillations when being at a local maximum, possibly because it tends to fall quickly as soon as the market receives some perception of price recovery. When these perceptions become contradicted by short-term events, the volatility index sharply increases again. The market only started recovering in October 2002 starting at that point a sustained upward trend that took IBEX from 5368 on October 1st, 2002, to 14974 on April 5th, 2007. 


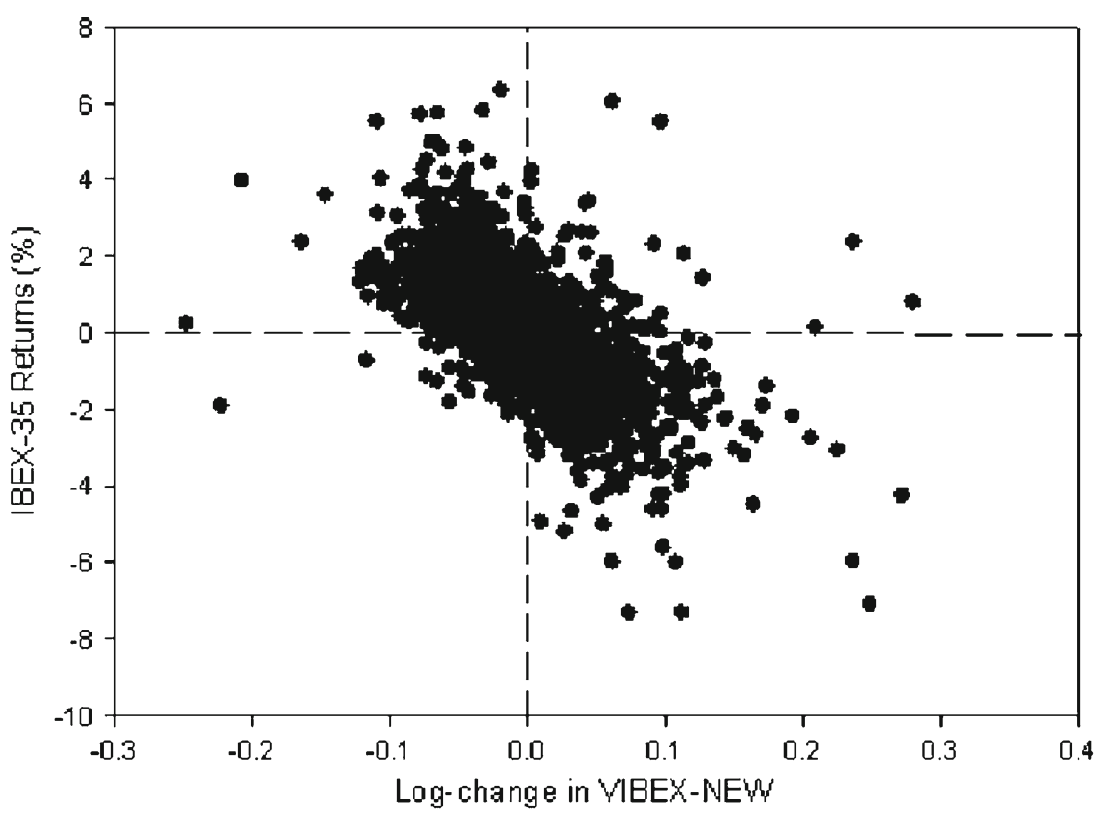

Fig. 3 Log-changes in VIBEX-NEW (\%) versus log-changes in IBEX-35. Daily data

This descriptive analysis suggests a negative relationship between returns and volatility, which is far from stable or clearly defined. However, a scatter diagram of daily IBEX-35 returns against daily changes in the logarithm of the VIBEX-NEW volatility index (see Fig. 3) suggests a clear, negative relationship between them. Indeed, linear correlation between daily returns and volatility changes over the whole sample period is -0.657 , just a bit higher in the second part of the sample. ${ }^{10}$ This suggests a closer relationship between the market and volatility indices at high frequencies than at low frequencies, which is an important consideration for a practical use of the volatility index.

\subsection{The return-volatility relationship: statistical analysis}

To quantify the contemporaneous relationship between daily changes in stock prices and in volatility, we estimate a common linear projection (9) of daily returns $\nabla \ln \left(I B E X_{t}\right)$ on daily changes in the volatility index $\left(\nabla Z_{t}\right) .{ }^{11}$ Some articles in the literature define this relationship in an inverse order. We define the volatility index changes as the independent variable because we would like to conclude on the information

\footnotetext{
10 Before and after August 2002.

11 Note that we use the nomenclature used by Box et al. (2008) to refer to the first regular difference. That is, $\nabla X_{t}=(1-L) \cdot X_{t}=X_{t}-X_{t-1}$.
} 
Table 5 Estimation results: the relationship between IBEX-35 returns and volatility index daily changes

\begin{tabular}{|c|c|c|c|c|c|c|c|c|}
\hline$\nabla Z$ (Indep. variable) & $\hat{\beta}_{0}$ & $\hat{\beta}_{0}^{+}$ & $\hat{\beta}_{1}$ & $\hat{\beta}_{1}^{+}$ & $\bar{R}^{2}$ & $\mathrm{~T}$ & $\hat{\sigma}_{\varepsilon}^{2}$ & DW \\
\hline \multirow[t]{2}{*}{$\nabla V I B E X-N E W(01 / 97-03 / 07)$} & $\begin{array}{l}0.040 \\
(0.021)\end{array}$ & & $\begin{array}{c}-0.762 \\
(0.055)\end{array}$ & & 0.43 & 2,574 & 1.1169 & 1.9680 \\
\hline & $\begin{array}{l}0.257 \\
(0.060)\end{array}$ & $\begin{array}{c}-0.527 \\
(0.102)\end{array}$ & $\begin{array}{c}-0.654 \\
(0.093)\end{array}$ & $\begin{array}{c}0.056 \\
(0.010)\end{array}$ & 0.45 & 2,574 & 1.1076 & 1.9476 \\
\hline \multirow[t]{2}{*}{$\nabla B M K 22(01 / 97-03 / 07)$} & $\begin{array}{c}0.042 \\
(0.028)\end{array}$ & & $\begin{array}{c}-0.046 \\
(0.029)\end{array}$ & & 0.00 & 2,574 & 1.9573 & 1.9520 \\
\hline & $\begin{array}{c}0.065 \\
(0.045)\end{array}$ & $\begin{array}{c}-0.057 \\
(0.063)\end{array}$ & $\begin{array}{c}-0.038 \\
(0.045)\end{array}$ & $\begin{array}{l}0.015 \\
(0.066)\end{array}$ & 0.00 & 2,574 & 1.9582 & 1.9513 \\
\hline \multirow[t]{2}{*}{$\nabla V I B E X-N E W(01 / 01-11 / 05)$} & $\begin{array}{l}0.001 \\
(0.028)\end{array}$ & & $\begin{array}{c}-0.862 \\
(0.121)\end{array}$ & & 0.47 & 1,227 & 1.0179 & 2.0788 \\
\hline & $\begin{array}{c}0.270 \\
(0.098)\end{array}$ & $\begin{array}{c}-0.693 \\
(0.189)\end{array}$ & $\begin{array}{c}-0.730 \\
(0.175)\end{array}$ & $\begin{array}{c}0.117 \\
(0.201)\end{array}$ & 0.51 & 1,227 & 0.9449 & 2.0225 \\
\hline \multirow[t]{2}{*}{$\nabla B M K 22(01 / 01-11 / 05)$} & $\begin{array}{l}0.012 \\
(0.039)\end{array}$ & & $\begin{array}{c}-0.016 \\
(0.043)\end{array}$ & & 0.00 & 1,227 & 1.9184 & 2.0532 \\
\hline & $\begin{array}{c}-0.014 \\
(0.091)\end{array}$ & $\begin{array}{c}-0.048 \\
(0.091)\end{array}$ & $\begin{array}{c}-0.081 \\
(0.067)\end{array}$ & $\begin{array}{l}0.016 \\
(0.098)\end{array}$ & 0.00 & 1,227 & 1.9164 & 2.0561 \\
\hline \multirow[t]{2}{*}{$\nabla I V C(01 / 01-11 / 05)$} & $\begin{array}{l}0.015 \\
(0.036)\end{array}$ & & $\begin{array}{c}-0.210 \\
(0.054)\end{array}$ & & 0.09 & 1,197 & 1.7506 & 2.1735 \\
\hline & $\begin{array}{l}0.370 \\
(0.091)\end{array}$ & $\begin{array}{c}-0.625 \\
(0.113)\end{array}$ & $\begin{array}{c}-0.055 \\
(0.103)\end{array}$ & $\begin{array}{c}-0.132 \\
(0.107)\end{array}$ & 0.11 & 1,197 & 1.6716 & 2.2282 \\
\hline
\end{tabular}

Estimation method is OLS with Newey-West Covariance Matrix (lag=1)

included (in a change) in VIBEX-NEW.

$$
\nabla \ln \left(I B E X_{t}\right)=\beta_{0}+\beta_{1} \nabla Z_{t}+u_{t}
$$

Estimation results in Table 5 show a negative and significant slope estimate, as expected from an investor fear gauge. The negative relationship is in line with similar ones estimated by Whaley (2000), Deutsche Borse (2007) and Skiadopoulos (2004) for the US, German and Greek volatility indices, respectively.

Given the small value estimated for the constant (see $\hat{\beta}_{0}$ ), we could conclude that this regression essentially associates positive returns with decreases in volatility, and negative returns with increases in the volatility index. In particular, it is possible to conclude that, for each point increase in volatility the IBEX-35 falls on average by $-0.76 \%$ and the opposite is estimated to happen when volatility decreases.

To be somewhat more precise in describing the relationship between IBEX35 returns and daily changes in the level of VIBEX-NEW, we explore the possibility that this relationship might be asymmetric with respect to the sign in VIBEX-NEW change. As we mentioned, Whaley (2000), Giot (2005), Simon (2003), and Skiadopoulos (2004) find that, for different financial markets, the stock market return magnitude, associated with a given change in the volatility index, depends on the sign of this change. To search for possible evidence of an asymmetry, we extend model (9) to model (10) by defining a dummy variable $D_{t}^{+}=1$ if $\nabla Z_{t}>0$, and $D_{t}^{+}=0$ otherwise. This model allows for a change in the model drift and slope for different signals in the $Z_{t}$ change.

$$
\nabla \ln I B E X_{t}=\beta_{0}+\beta_{0}^{+} D_{t}^{+}+\beta_{1} \nabla Z_{t}+\beta_{1}^{+}\left(D_{t}^{+} \cdot \nabla Z_{t}\right)+v_{t}
$$


Estimation results for Model (10) reported in Table 5 suggest that the effects on the Spanish market of volatility changes are symmetric around zero. In fact, a reduction of one point in VIBEX-NEW is associated with a rise in the index of $+0.91 \%$, while an increase of one point in the volatility index is associated with a fall in the market index of similar size, $-0.87 \%$. Hence, in spite of the statistical significance of the coefficient of the signed slope $\left(\hat{\beta}_{1}^{+}\right)$, the implied effects on market returns of volatility increases and decreases of the same size are very similar, and there is not much evidence of an asymmetric relationship. As further evidence, the median values for daily volatility increase (1,164 days in the sample) and decreases (1,409 days) are also similar, +0.53 and -0.46 , Consequently, the implied average return that emerges from the estimated model is similar in both cases, around $0.56 \%$ in absolute value. That is, in fact, quite close to the actual sample median returns of $-0.63 \%$ for days when the volatility index increases, and $+0.60 \%$ for days when VIBEX-NEW decreases, reflecting again the good fit of the model. Note that Skiadopoulos (2004) estimates $R^{2}=0.04$ for a regression similar to (10). We report $R^{2}=0.40$ for the negative relationship between the two variables; that is, a more robust relationship between stock index returns and daily volatility index changes.

The model (10) has the somewhat unpleasant feature, however, of being discontinuous at a zero volatility change. This is reflected in the fact that the expected return for a day with a very low volatility increase is $-0.270\left(\right.$ see $\left.\hat{\beta}_{0}+\hat{\beta}_{0}^{+}\right)$, while the expected return for days of very low decreases in volatility is positive, 0.258 (see $\hat{\beta}_{0}$ ). But if we eliminate that discontinuity by restricting the intercept terms in (9) and (10) to be the same, the effect of the estimated dummy slope $\left(D_{t}^{+} \cdot \nabla Z_{t}\right)$ becomes numerically irrelevant, and we end up with the symmetric regression we initially estimated, which discriminates perfectly between positive/negative returns and decreases/increases in volatility. Furthermore, both regressions (with and without asymmetric effects only in slope) fit the data very similarly. This is also reflected in the same adjusted R-squared and in the linear correlation coefficient essentially, equal to 1 between their respective residuals. Moreover, Skiadopoulos (2004) reports $R^{2}=0.04$ for a similar model to (10). We report $R^{2}=0.45$, which suggests a better fit and also that only $45 \%$ of IBEX-35 returns variance is explained by VIBEX-NEW changes variance.

Two facts should be noted before continuing. Gonzalez-Perez and Novales (2009) show that the relationship between daily changes in VIX, VDAX-NEW, VSMI and its respective stock indices returns SPX, DAX, SMI is symmetric in terms of the volatility change sign, over a common sample from January 2000 to March 2008. This result is not in opposition to the ability of these indices to inform on the investor fear gauge. Whaley (2000) and Figlewski and Wang (2000) ${ }^{12}$ report an asymmetric relationship between OEX returns and VXO changes, but Whaley does not report $t$ statistics for the model parameters. Figlewski and Wang (2000) only conclude that the asymmetry is defined in the relationship in terms of the sign of stock index return, and both articles conclude that there is information content in a model-based volatility index. The market uncertainty or enthusiasm (more reflected in OTM than in ATM option prices) make more noise in the model-free than the model-based volatility index so, on

12 Finance Working Paper (New York University, Stern School of Business). 
average, the sign of daily model-free volatility changes can vary more than the underlying return sign (it depends on the period of time), generating no enough evidence in data in favor of such asymmetric relationship.

Since the realized volatility is less noisy than the (model-free) volatility index, Figlewski and Wang (2000) and Whaley (2009) ${ }^{13}$ study whether the relationship is asymmetric, in terms of the returns sign, and conclude in favor of this. Granger causality in international volatility indices run in both directions (see Gonzalez-Perez and Novales (2009)): from underlying returns to volatility index changes, and from volatility index changes to underlying returns, so we decide to estimate the model defined in (11) to complete the study on the relationship between IBEX-35 returns and VIBEX-NEW daily changes, where $D_{t}^{-}=1$ when $\nabla \ln I B E X_{t}<0$ and $D_{t}^{-}=0$, otherwise. According to our results, parameters $\beta_{0}$ and $\beta_{0}^{-}$are not significantly different from zero, which lets us conclude that an IBEX return of $-1 \%$ corresponds with a change in VIBEX-NEW of 0.74 points, while an IBEX return of $+1 \%$ corresponds with a decrease in VIBEX-NEW of -0.44 . Therefore, although the relationship between VIBEX-NEW and IBEX-35 seems to be symmetric to the sign in the VIBEXNEW change, this relationship is asymmetric on the sign in the IBEX-35 returns, as is expected for an investor fear gauge (see Whaley 2009).

$$
\begin{aligned}
\nabla Z_{t}= & \underset{(0.0451)}{-0.0789}-0.1083 D_{t}^{-}-\underset{(0.0645)}{0}-0.4419 \nabla \ln I B E X_{t} \\
& -\underset{(0.0509)}{0.2954}\left(D_{t}^{-} \cdot \nabla \ln I B E X_{t}\right)+\hat{\varepsilon}_{t}
\end{aligned}
$$

\subsection{The investor fear gauge: other volatility measures}

Volatility index is not the only measure used in the market to approximate the investor fear gauge, so in this subsection we compare the relationship between changes in such alternative volatility measures and IBEX-35 returns, to determine how far is the VIBEX-NEW information capability from these variables. Therefore, we estimate models (9) and (10) considering other common volatility measures to compare the information content in VIBEX-NEW with the information content in those alternative measures: IVC and BMK22.

The first alternative volatility measure, called IVC, is an implied volatility indicator we compute daily as the average of the Black (1976) NTM 5\% intraday implied volatility from call trading prices. We focus on the $\operatorname{NTM}(5 \%)$ call options to minimize the bounce effect in the IVC. Note that, although IVC and VIBEX are model-based indicators, IVC is not equivalent to the VIBEX index. Main differences between VIBEX and IVC are the followings:

(i) VIBEX is computed from call and put settlement prices, and IVC is computed from intraday call option prices,

\footnotetext{
13 Whaley (2009), who only reports such asymmetric relationship (between VIX changes and SPX returns), that is, in terms of the SPX return sign.
} 
(ii) VIBEX is based on the two closest to 22 trading days maturities and IVC is based on option prices with maturity in between 8 and 60 trading days (more liquid in the Spanish option market).

(iii) VIBEX is computed from closer to ATM options and IVC from NTM(5\%) options.

We use IVC also to infer significant differences between the information content in intraday and closing option prices, as well as between model-based and model-free volatility indicators. Due to the data availability we only can compute IVC from January 1,2001 to 11 in November $2005 .{ }^{14}$ so we use this subsample to compare the indices. ${ }^{15}$

The second alternative measure is a benchmark ${ }^{16}$ volatility indicator we label BMK22, and compute as the standard deviation of twenty two past closing IBEX-35 returns. BMK22 is available for the entire sample, from January 1997 to March 2007. Figure 4 shows the relationship between IVG, IVC and BMK22 with the model-free volatility index VIBEX-NEW.

Table 5 shows estimated models (9) and (10) for $Z$ equal to IVC and BMK22. We use 1997-2007 to compare VIBEX-NEW and BMK22, and 2001-2005 to compare VIBEX-NEW, IVC and BMK22. As we can see, changes in recent historical volatility, reflected in BMK22, do not show a clear contemporaneous relationship with market returns, contrary to VIBEX-NEW. Slope is reduced or not significant when asymmetry is considered, contrary to VIBEX-NEW, which shows a clear contemporaneous relationship with market returns over the same period. This is an interesting piece of empirical evidence. It shows that the strong contemporaneous correlation between VIBEX-NEW and market returns is not just due to the fact that variables, market returns and changes in the volatility index reflect the recent behavior of market volatility, as would be captured by BMK22. The evidence is therefore consistent with VIBEX-NEW being able to capture current market events, and possibly the market's perception of risk, more than being a pure reflection of past events.

Similar results emerge when we compare VIBEX-NEW and BMK22 in the second subsample (2001-2005). Regarding IVC, despite some $t$ statistics on parameters being larger than 2.0 in absolute value, the fit of the contemporaneous regression is very poor $\left(R^{2}=0.09\right)$, contrary to what happens over the same period with VIBEXNEW ( $R^{2}=0.47$ and $\left.R^{2}=0.51\right)$. In particular, it is interesting to note that estimated average returns associated with a unit change in volatility index is around $1 \%$ (see $\left(\hat{\beta}_{0}+\hat{\beta}_{0}^{+}+\hat{\beta}_{1}+\hat{\beta}_{1}^{+}\right)$and $\left(\hat{\beta}_{0}-\hat{\beta}_{1}\right)$ for VIBEX-NEW), whereas the estimated average returns associated to a unit change in IVC is around $0.4 \%\left(\right.$ see $\left(\hat{\beta}_{0}+\hat{\beta}_{0}^{+}+\hat{\beta}_{1}+\hat{\beta}_{1}^{+}\right)$and $\left(\hat{\beta}_{0}-\hat{\beta}_{1}\right)$ for IVC), which denotes a higher reaction of IBEX-35 returns to a one-point change in VIBEX-NEW than to the same change in IVC value.

\footnotetext{
14 The strong change in the intraday registers format and content provided by the Official Spanish Clearing House, which makes much difficult to manipulate such big data base to compute the IVC.

15 We are working on extending this exercise to the entire sample. Nevertheless, we expect to obtain the same results for 2001-2005 (five years of data) and 1997-2007 samples (more than nine years of data).

16 This is the simplest volatility measure to use in current time to infer current volatility and current perception of risk in the market.
} 

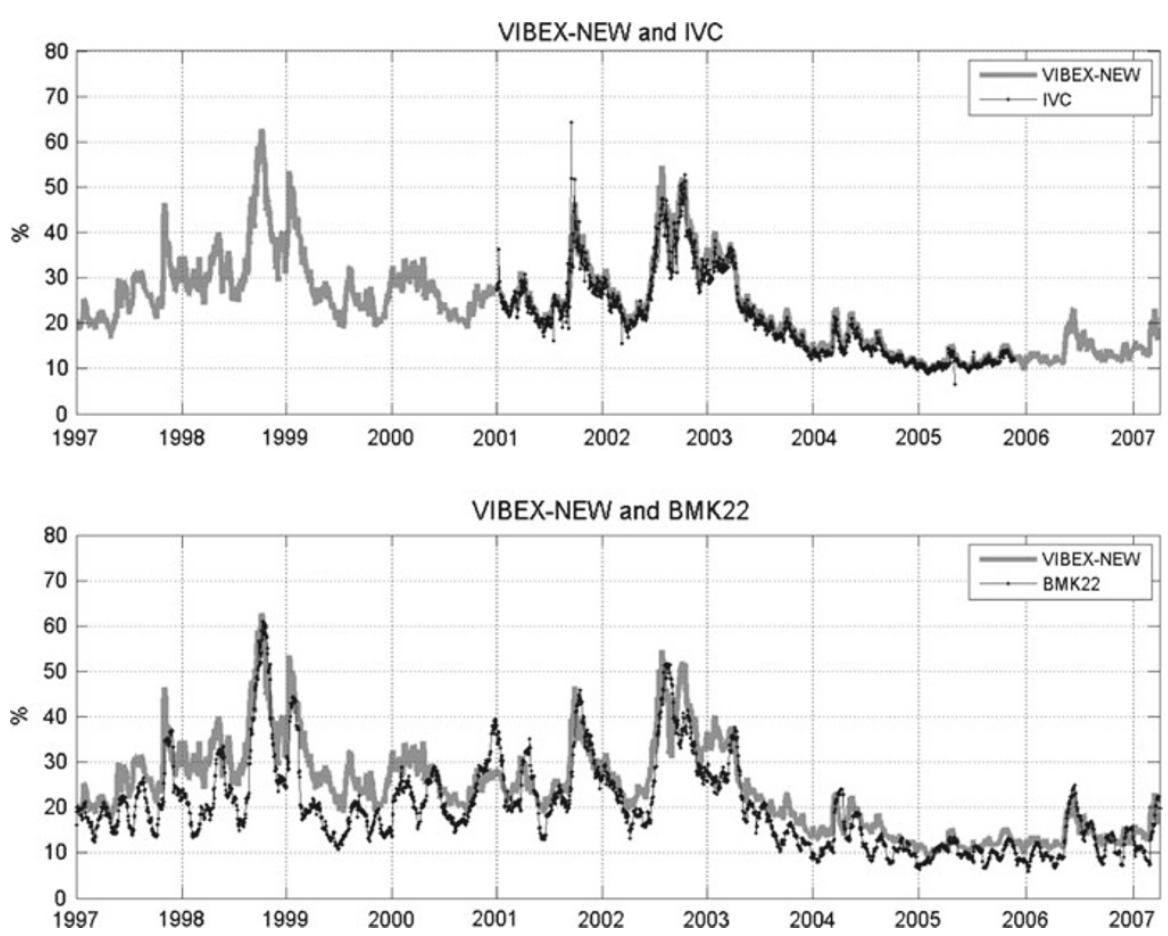

Fig. 4 Volatility measures (IVG, IVC, BMK22) versus VIBEX-NEW

Summarizing, the different nature of the relationship with returns estimated for the two alternative volatility indices, IVC and BMK22, relative to VIBEX-NEW, shows the incremental information contained in VIBEX-NEW relative to these alternative, standard indicators of market volatility, and confirms VIBEX-NEW as a potential candidate for an investor fear gauge and an official volatility index in the Spanish financial market.

The return-volatility relationship in (9) could incorporate a dynamic structure, by including lags of the respective explanatory variable (as in Skiadopoulos 2004). Indeed, estimates of such a dynamic specification, not shown here, provide statistical significance for some of the lagged coefficients. However, the individual coefficients estimated on lagged variables are much smaller than the coefficient on the contemporaneous value of the explanatory variable. Furthermore, the correlation coefficient between the residuals of the dynamic and the static models is above 0.99, suggesting that the explanatory power of both specifications is the same. This is the case when volatility is used to explain market returns as well as the other way around. However, the difficulty in discriminating the dynamics of the relationship between return and volatility is clear. A vector autoregression (VAR) with the two variables needs two lags for the residuals to be free of autocorrelation. In that system, the $F$ statistic to test for Granger causality running from the daily volatility changes to market returns is 5.35 , with a $p$ value of 0.069 , while the statistic for the alternative causality direction is 9.73 , with a $p$ value of 0.008 . These results suggest that there might be more interesting 
dynamics from market returns to the volatility index, than the other way around. It could be taken as evidence that market returns over the past few days influence the perception of risk of market participants when deciding on option prices, moreover when these imply significant stock index movements. This preliminary result is similar to the conclusion reported by Hibbert et al. (2008), who say “... both the presence and magnitude of the negative relation and the asymmetry between returns and implied volatility are most closely associated with extreme changes in the index returns" and support the VIBEX-NEW as a possible Spanish official volatility index.

\section{The volatility index as a predictor of future volatility}

The volatility index is constructed to reflect the current level of volatility expected by the market for a delimited future period of time, and not with a forecasting goal in mind. However, a volatility index like VIBEX-NEW, which is constructed from option prices, might be expected also to be positively related to the future level of IBEX35 returns volatility. This point is reflected in the literature, where many studies analyze the forecasting ability of official volatility indices with different results (see Poon and Granger 2008). On the other hand, the difference between model-free volatility index and the (future) realized volatility in the period for which the index is computed informs about the volatility risk premium in such financial market (see Bollerslev et al. 2009). These facts justify the analyzes included in this section.

In this section we proceed in two steps. First, we examine the ability of each indicator to be a unbiased forecaster of the future IBEX-35 volatility. In this case, we examine the stability of the loss function dynamic for the VIBEX-NEW, which informs about the stability of the volatility risk premium in the Spanish Financial Market. Second, we let for a bias and estimate for each day a feasible corrected volatility indicator to conclude on the ability of each indicator to anticipate the IBEX-35 volatility in the next 22 trading days.

In this article we use DT22 as the proxy for IBEX-35 volatility with the intention of evaluating VIBEX-NEW forecasting ability from a statistical point view. This is called the DT22 indicator, ${ }^{17}$ and it is defined as the annualized standard deviation of daily IBEX35 returns $\left(r_{t}\right)$ over the next 22 market days ${ }^{18}$ (see (12)). To avoid mistakes in the interpretation, we have to note that the sub-index $t$ in (12) is in reference to IBEX-35 volatility in the 22 trading days following $t$. This means that $D T 22_{t}$ is not known at time $t$, but in $t+22$.

$$
D T 22_{t}=\sqrt{250 \frac{\sum_{j=1}^{22}\left(r_{t+j}-\bar{r}\right)^{2}}{21}}
$$

\footnotetext{
17 A volatility proxy constructed with intra-day data might be preferable, but we lack that kind of data for part of the sample. Nevertheless, the forecasting ability of VIBEX-NEW over the 2001-2003 period is similar when we use either daily or intraday returns to calculate measures of realized volatility for IBEX35.

18 Notice that, in spite of the $t$ subindex in (12) this variable uses information which will not be fully known until $t+22$. The $t$ subindex indicates that is the indicator of future volatility that we wish to anticipate at time $t$.
} 
Three alternative volatility measures are considered in this section to conclude on the relative ability of VIBEX-NEW to approximate future IBEX-35 volatility. These measures have been used in previous sections and are the most frequently used in literature to comment on the relative volatility index forecasting ability: (i) two model-based volatilities, one from the option market (IVC) and the other from the stock market (IVG), and (ii) a benchmark measure, BMK22.

Volatility measures IVC and BMK22 are computed as stated in Sect. 3.2. IVG comes from averaging conditional variance forecasts from a $\operatorname{GARCH}(1,1)$ model over the 22 days following model estimation. ${ }^{19}$ Although a GARCH $(1,1)$ might not be the most convenient model for IBEX-35 returns conditional variance, we decide to compute IVG by using this model because this is the most used model in the market to measure asset volatility. The proximity to one of the sum of $\operatorname{GARCH}(1,1)$ parameter $\alpha+\beta$ makes that we only can estimate IVG from January 2001 to March 2007. This explains that we use this sample to reach conclusions on the relative forecasting ability of VIBEX-NEW related to the one in GARCH $(1,1)$ volatility measure.

Is important to mention that, as DT22 and BMK22 have been defined, BMK22 is actually equal to the DT22 indicator, lagged 22 periods $\left(B M K 22_{t}=D T 22_{t-22}\right.$, for all $t$ ). So, it is possible to anticipate that BMK22 will produce good forecasts if our measure of IBEX-35 returns volatility, DT22, shows sufficient stability. On the other hand, the forecasting ability of IVC refers to the extensively analyzed issue of the forecasting ability of intra-day implied volatility. From the forecasting point of view, we could think of VIBEX-NEW as occupying an intermediate position between summarizing implied volatility at a point in time, as IVC, since it is obtained from some option prices, and capturing some aspects of past IBEX-35 returns volatility, as BMK22.

To statistically compare volatility measures with future volatility we present Table 6 . This Table shows main descriptive statistics for VIBEX-NEW, IVC, IVG, BMK22 and DT22 in available samples. First, statistics for BMK22 and DT22 are very similar, as expected, since BMK22 is just a lag of the DT22 time series. Second, VIBEX-NEW series frequently adopts higher values than DT22, which reflects the volatility risk premium, and points to the VIBEX-NEW forecasting bias. Third, contrary to VIBEXNEW, IVG seems to adopt lower values than DT22, which is suggested by similar kurtosis and a lower value in median and mean than in DT22. Finally, despite the different ability to inform on current risk, IVC statistics are not very different from those for VIBEX-NEW, which could suggest that official closing option prices and intraday prices contain similar information on future volatility. The analysis that follows will help us to clarify this issue.

\subsection{Volatility indicators and future realized volatility}

This exercise explores the ability of each of the three volatility indicators as an unbiased predictor of future realized volatility. As a first sight to the forecasting ability

\footnotetext{
19 It is common to find this volatility measure as a possible competitor of volatility indices in forecasting stock index volatility. Results in literature about the best volatility measure are mixed.
} 
Table 6 Descriptive statistics

\begin{tabular}{llllll}
\hline & DT22 & VIBEX-NEW & IVC & IVG & BMK22 \\
\hline Mean & 19.87 & 23.68 & 21.27 & 16.05 & 19.90 \\
Median & 18.26 & 23.02 & 19.82 & 15.78 & 18.33 \\
Skewness & 1.26 & 0.81 & 0.89 & 1.21 & 1.26 \\
Kurtosis & 4.84 & 3.66 & 3.33 & 6.83 & 4.84 \\
$\mathrm{p}(95)$ & 39.17 & 41.53 & 39.41 & 22.70 & 39.17 \\
$\mathrm{p}(75)$ & 24.37 & 29.01 & 26.84 & 18.01 & 24.37 \\
$\mathrm{p}(25)$ & 12.49 & 15.27 & 13.11 & 13.23 & 12.52 \\
$\mathrm{p}(5)$ & 8.41 & 11.35 & 10.34 & 11.17 & 8.41 \\
$T$ & 2,575 & 2,575 & 1,198 & 1,575 & 2,575 \\
\hline
\end{tabular}
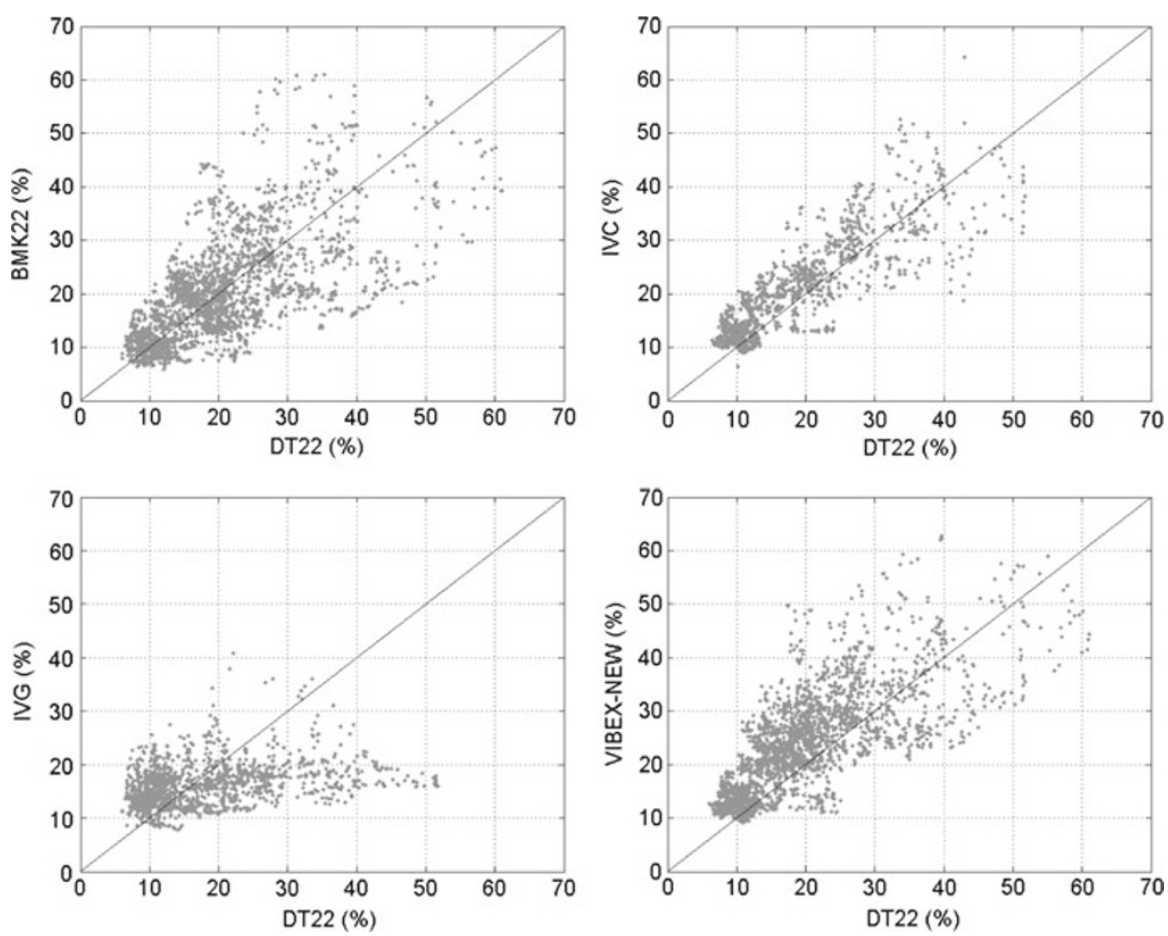

Fig. 5 Original volatility indicators versus DT22. Daily data

of indicators we present Fig. 5. This Figure shows scatter diagrams relating daily VIBEX-NEW, IVC, IVG and BMK22 indicators with the daily DT22 time series. Remember that these relationships are between volatility indicators observed at time $t$; and volatility realized over the $(t+1 ; t+22)$ period. Even though the four graphs display a positive relationship between the volatility indicators and future IBEX35 volatility, this does not seem to be very stable over time, especially between IVG and DT22. 
Two absolute loss functions (MAE and RMSE), and two percent loss functions (MAPE and RMSPE) are computed to compare the forecasting ability of different volatility indicators, called $Z$.

$$
\begin{aligned}
\hat{\varepsilon}_{t} & =D T 22_{t}-Z_{t} ; \quad \hat{\xi}_{t}=\frac{D T 22_{t}-Z_{t}}{D T 22_{t}} \\
M A E & =\frac{1}{N} \sum_{t=1}^{N}\left|\hat{\varepsilon}_{t}\right| ; \quad M A P E=\frac{1}{N} \sum_{t=1}^{N}\left|\hat{\xi}_{t}\right| \\
R M S E & =\sqrt{\frac{1}{N} \sum_{t=1}^{N} \hat{\varepsilon}_{t}^{2}} ; \quad R M S P E=\sqrt{\frac{1}{N} \sum_{t=1}^{N} \hat{\xi}_{t}^{2}}
\end{aligned}
$$

The unstable relationship between DT22 and the volatility measures is confirmed when we observe that relative and nominal loss functions, computed with 250 daily forecasting errors, change significantly over the time for each volatility indicator. We then decide (i) to daily compute MAE, RMSE, MAPE and RMSPE functions by considering last 250 daily forecasting errors, as is described below, and (ii) use these series to study VIBEX-NEW position in the forecasting ranking.

$$
\begin{aligned}
M A E_{t} & =\frac{1}{250} \sum_{i=1}^{250}\left|\hat{\varepsilon}_{t-i}\right| ; \quad M A P E_{t}=\frac{1}{250} \sum_{i=1}^{250}\left|\hat{\xi}_{t-1}\right| \\
\text { MMSE }_{t} & =\sqrt{\frac{1}{250} \sum_{i=1}^{250} \hat{\varepsilon}_{t-i}^{2} ;} \quad \operatorname{RMSPE}_{t}=\sqrt{\frac{1}{250} \sum_{i=1}^{250} \hat{\xi}_{t-i}^{2}}
\end{aligned}
$$

Figure 6 shows (i) loss function series $\left\{M A E_{t}\right\}_{t=1}^{T},\left\{R M S E_{t}\right\}_{t=1}^{T},\left\{M A P E_{t}\right\}_{t=1}^{T}$ and $\left\{R M S P E_{t}\right\}_{t=1}^{T}$ for each volatility indicator. Table 5 shows main descriptive statistics for each loss function (mean, median, standard deviation, minimum and maximum values), as well as the mean value for loss functions in each year.

We conclude on differences between loss functions over the whole sample attending to (i) the time evolution and main descriptive statistics of loss functions reported in Tables 7 and 8, and on (ii) the Diebold and Mariano (1995) statistics, included in Table 9.

Note in Fig. 6 that the two volatility indicators computed in the Option Market (IVC and VIBEX-NEW) generate better forecasts than the one computed in the Stock Market (IVG), since loss functions for IVC and VIBEX-NEW achieve lower values than for IVG. This result is confirmed by the Diebold and Mariano statistics. These are reported in Table 9, for the common sample to pairwise indexes, and in Table 10, for the common sample to all indexes.

In fact, the worst result over all the measures is confirmed for IVG, which shows higher loss mean and median related to the rest of the indices. On the other hand, IVC forecasting ability seems to be higher than VIBEX-NEW, not only when MAE and RMSE are considered but also when we compute the MAPE and RMSPE loss 

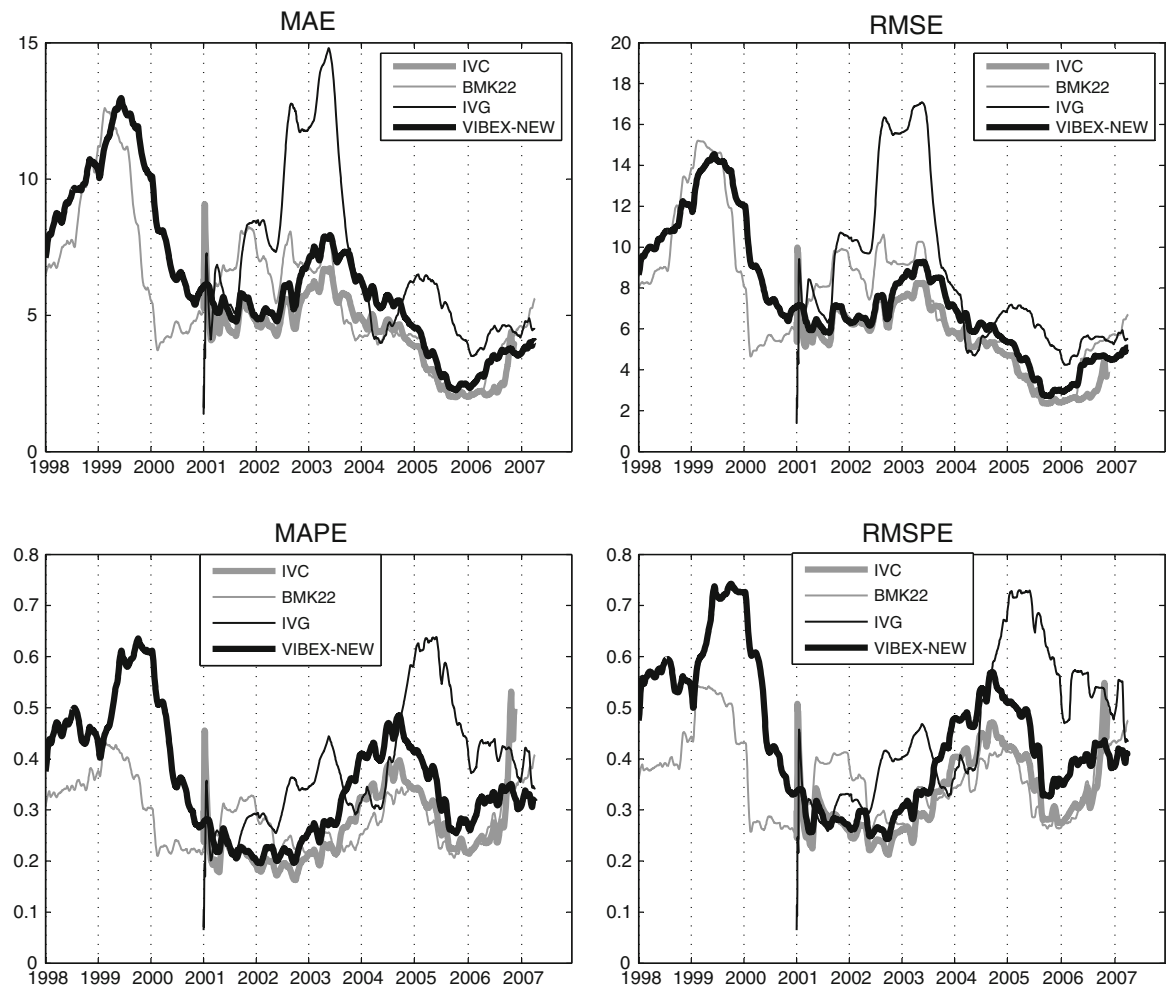

Fig. 6 Loss functions on forecasting error for each volatility indicator: each day loss function is computed by considering last 250 forecasting error

functions. Sign and value of Diebold and Mariano (1995) statistics in Tables 9 and 10 reveal that IVC is better unbiased forecaster than VIBEX-NEW and IVG and at least equal than BMK22, when RMSPE and MAPE are considered. This fact would evidence the importance to consider intraday quotes in option market to forecast volatility. Finally, Diebold and Mariano (1995) statistics also suggest that IVG is always a worst unbiased forecaster than Option-Market-based volatility indicators IVC and VIBEXNEW and than benchmark BMK22.

Differing by years, Tables 7 and 8 show that annual expected VIBEX-NEW loss functions are smaller than annual expected BMK22 loss functions only in 2001 and 2002, which would suggest that BMK22 is a better unbiased predictor than VIBEXNEW. In particular, mean VIBEX-NEW MAPE in 1998-2000 and 2003-2006 is 10 more units in percentage than the ones for BMK22. Nevertheless, we have to remember that BMK22 is the past value of DT22 (future IBEX-35 volatility), and it is clear that DT22 shows persistence over time, which could explain this result. This favorable result for BMK22 could not be repeated for another measure of future IBEX-35 returns volatility.

Loss functions evolution over the entire sample shows that forecast errors in absolute terms seem to be lower in the last part of the sample than in the first part (see MAE and RMSE figures), when the DT22 level (and dispersion) is lower. Nevertheless, as 
Table 7 Loss functions: MAE and RMSE

\begin{tabular}{|c|c|c|c|c|c|c|c|c|}
\hline & \multicolumn{4}{|l|}{ MAE } & \multicolumn{4}{|c|}{ RMSE } \\
\hline & IVC & BMK22 & IVG & VIBEX-NEW & IVC & BMK22 & IVG & VIBEX-NEW \\
\hline \multicolumn{9}{|c|}{ Whole sample } \\
\hline Mean & 4.65 & 5.82 & 6.87 & 6.33 & 5.79 & 7.44 & 8.46 & 7.47 \\
\hline Median & 4.69 & 5.42 & 6.01 & 5.73 & 5.90 & 6.91 & 6.97 & 6.81 \\
\hline$\sigma$ & 1.17 & 2.52 & 3.00 & 2.68 & 1.51 & 3.20 & 3.81 & 3.01 \\
\hline Min & 2.00 & 1.91 & 1.37 & 2.25 & 2.36 & 2.28 & 1.37 & 2.71 \\
\hline \multirow[t]{3}{*}{ Max } & 9.08 & 12.64 & 14.84 & 12.97 & 9.98 & 15.42 & 17.11 & 14.56 \\
\hline & \multicolumn{4}{|c|}{ MAE (mean) } & \multicolumn{4}{|c|}{ RMSE (mean) } \\
\hline & IVC & BMK22 & IVG & VIBEX-NEW & IVC & BMK22 & IVG & VIBEX-NEW \\
\hline \multicolumn{9}{|l|}{ Each year } \\
\hline 1998 & & 8.37 & & 9.32 & & 10.17 & & 10.69 \\
\hline 1999 & & 10.02 & & 11.63 & & 13.11 & & 13.49 \\
\hline 2000 & & 4.51 & & 6.87 & & 5.62 & & 7.94 \\
\hline 2001 & 5.01 & 6.87 & 6.30 & 5.40 & 6.20 & 8.33 & 8.06 & 6.49 \\
\hline 2002 & 4.98 & 6.82 & 9.93 & 5.58 & 6.68 & 9.05 & 12.83 & 7.01 \\
\hline 2003 & 5.84 & 5.93 & 10.91 & 7.20 & 7.23 & 8.04 & 13.26 & 8.43 \\
\hline 2004 & 4.51 & 4.28 & 5.09 & 5.43 & 5.31 & 5.55 & 6.04 & 6.11 \\
\hline 2005 & 2.72 & 2.64 & 5.46 & 3.12 & 3.31 & 3.26 & 6.24 & 3.82 \\
\hline 2006 & & 3.33 & 4.19 & 3.24 & & 4.35 & 5.17 & 4.05 \\
\hline $2007 *$ & & 4.94 & 4.63 & 3.87 & & 6.09 & 5.64 & 4.82 \\
\hline
\end{tabular}

Original volatility indicators: mean, median, standard deviation, minimum and maximum are provided for the entire sample, as well as the mean value of loss functions in each year

* From January 2007 to March 2007

can be better seen in percentage terms (see MAPE and RMSPE figures), this was due in part to the general restraint in the level of volatility over that period, and not necessarily to the better relative forecasting performance of these volatility indicators, which is not always considered in literature.

Despite the better performance of IVC, related to the other indicators, MAPE values in Fig. 6 are never below 20\%, vary significantly over the time and occasionally go well above that level, seriously questioning their usefulness as unbiased predictors of future volatility. Is it useful to use a volatility indicator with at least $20 \%$ mean forecasting error when this bias is not possible to anticipate? We need to introduce some bias correction in these volatility indicators before concluding and recommending them to investors or risk managers. That is the objective of the next subsection.

\subsection{Correcting for the forecast bias}

In the previous subsection we drew conclusions about a volatility indicator forecasting ability regarding different loss functions. In this section we propose a simple approach to test if the past forecasting bias (volatility risk premium) can be used to anticipate the future bias. 
Table 8 Loss functions: MAPE and RMSPE

\begin{tabular}{|c|c|c|c|c|c|c|c|c|}
\hline & \multicolumn{4}{|c|}{ MAPE } & \multicolumn{4}{|c|}{ RMSPE } \\
\hline & IVC & BMK22 & IVG & VIBEX-NEW & IVC & BMK22 & IVG & VIBEX-NEW \\
\hline \multicolumn{9}{|c|}{ Whole sample } \\
\hline Mean & 0.26 & 0.29 & 0.38 & 0.36 & 0.33 & 0.36 & 0.46 & 0.44 \\
\hline Median & 0.23 & 0.28 & 0.36 & 0.34 & 0.29 & 0.36 & 0.43 & 0.42 \\
\hline$\sigma$ & 0.07 & 0.06 & 0.11 & 0.11 & 0.07 & 0.08 & 0.13 & 0.13 \\
\hline Min & 0.16 & 0.20 & 0.06 & 0.20 & 0.21 & 0.25 & 0.06 & 0.24 \\
\hline \multirow[t]{3}{*}{ Max } & 0.46 & 0.44 & 0.64 & 0.64 & 0.51 & 0.54 & 0.73 & 0.74 \\
\hline & \multicolumn{4}{|c|}{ MAPE (mean) } & \multicolumn{4}{|c|}{ RMSPE (mean) } \\
\hline & IVC & BMK22 & IVG & VIBEX-NEW & IVC & BMK22 & IVG & VIBEX-NEW \\
\hline \multicolumn{9}{|l|}{ Each year } \\
\hline 1998 & & 0.35 & & 0.46 & & 0.40 & & 0.56 \\
\hline 1999 & & 0.38 & & 0.55 & & 0.50 & & 0.68 \\
\hline 2000 & & 0.23 & & 0.39 & & 0.28 & & 0.47 \\
\hline 2001 & 0.23 & 0.29 & 0.25 & 0.23 & 0.29 & 0.37 & 0.30 & 0.29 \\
\hline 2002 & 0.19 & 0.24 & 0.31 & 0.22 & 0.24 & 0.30 & 0.36 & 0.27 \\
\hline 2003 & 0.24 & 0.23 & 0.36 & 0.30 & 0.31 & 0.31 & 0.40 & 0.36 \\
\hline 2004 & 0.35 & 0.31 & 0.40 & 0.43 & 0.43 & 0.38 & 0.49 & 0.51 \\
\hline 2005 & 0.28 & 0.26 & 0.56 & 0.33 & 0.36 & 0.32 & 0.67 & 0.42 \\
\hline 2006 & & 0.28 & 0.41 & 0.32 & & 0.35 & 0.53 & 0.40 \\
\hline $2007 *$ & & 0.37 & 0.38 & 0.32 & & 0.45 & 0.50 & 0.41 \\
\hline
\end{tabular}

Original volatility indicators: mean, median, standard deviation, minimum and maximum are provided for the entire sample, as well as the mean value of loss functions in each year

* From January 2007 to March 2007

Table 9 Diebold and Mariano (1995) test

\begin{tabular}{|c|c|c|c|c|c|c|c|}
\hline & \multicolumn{3}{|c|}{ Loss function: $\varepsilon_{t}^{2}$} & & \multicolumn{3}{|c|}{ Loss function: $\left|\varepsilon_{t}\right|$} \\
\hline & BMK22 & IVG & VIBEX-NEW & & BMK22 & IVG & VIBEX-NEW \\
\hline$\overline{\text { IVC }}$ & $-8.33^{\sharp}$ & $-12.90^{\sharp}$ & $-9.78^{\sharp}$ & IVC & $-6.06^{\#}$ & $-15.85^{\sharp}$ & $-15.94^{\sharp}$ \\
\hline BMK22 & - & $-10.62^{b}$ & $0.57^{\dagger}$ & BMK22 & - & $-12.83^{b}$ & $-3.99^{\dagger}$ \\
\hline \multirow[t]{3}{*}{ IVG } & - & - & $11.71^{\sharp}$ & IVG & - & - & $12.77 \sharp$ \\
\hline & \multicolumn{3}{|c|}{ Loss function: $\xi_{t}^{2}$} & & \multicolumn{3}{|c|}{ Loss function: $\left|\xi_{t}\right|$} \\
\hline & BMK22 & IVG & VIBEX-NEW & & BMK22 & IVG & VIBEX-NEW \\
\hline IVC & $-1.56^{\sharp}$ & $-11.93^{\sharp}$ & $-18.76^{\sharp}$ & IVC & $-1.58^{\sharp}$ & $-14.86^{\sharp}$ & $-22.62^{\sharp}$ \\
\hline BMK22 & - & $-10.16^{b}$ & $-12.82^{\dagger}$ & BMK22 & - & $-12.49^{b}$ & $-11.83^{\dagger}$ \\
\hline IVG & - & - & $8.71^{\#}$ & IVG & - & - & $10.49 \sharp$ \\
\hline
\end{tabular}

Square and absolute value loss functions. Common samples by pairs $\sharp 02 / \mathrm{Jan} / 2001-18 /$ Nov/2005, ${ }^{b}$ 02/Jan/2001-30/Mar/2007, ${ }^{\dagger}$ 02/Jan/1997-30/Mar/2007 
Table 10 Diebold and Mariano (1995) test

\begin{tabular}{|c|c|c|c|c|c|c|c|}
\hline & \multicolumn{3}{|c|}{ Loss function: $\varepsilon_{t}^{2}$} & & \multicolumn{3}{|c|}{ Loss function: $\left|\varepsilon_{t}\right|$} \\
\hline & BMK22 & IVG & VIBEX-NEW & & BMK22 & IVG & VIBEX-NEW \\
\hline$\overline{\text { IVC }}$ & -8.33 & -12.90 & -9.78 & IVC & -6.06 & -15.85 & -15.94 \\
\hline BMK22 & - & -10.98 & 4.11 & BMK22 & - & -13.60 & -0.47 \\
\hline \multirow[t]{3}{*}{ IVG } & - & - & 11.18 & IVG & - & - & 11.63 \\
\hline & \multicolumn{3}{|c|}{ Loss function: $\xi_{t}^{2}$} & & \multicolumn{3}{|c|}{ Loss function: $\left|\xi_{t}\right|$} \\
\hline & BMK22 & IVG & VIBEX-NEW & & BMK22 & IVG & VIBEX-NEW \\
\hline IVC & -1.56 & -11.93 & -18.76 & IVC & -1.58 & -14.86 & -22.62 \\
\hline BMK22 & - & -10.39 & -6.06 & BMK22 & - & -13.07 & -6.42 \\
\hline IVG & - & - & 7.52 & IVG & - & - & 8.89 \\
\hline
\end{tabular}

Square and absolute value loss functions. Common sample (non-missing values in all the time series): 02/Jan/2001-18/Nov/2005

$$
D T 22_{t}=\beta_{0}+\beta_{1} Z_{t}+\varepsilon_{t}
$$

It is standard in the literature to use a good fit in regression (15) to conclude in favor of the forecasting ability of the volatility indicator $Z$. That is inappropriate for two reasons: one of them is the standard argument that a good fit does not necessarily imply a good forecasting performance, since $\beta_{0}$ and $\beta_{1}$ cannot be computed at time $t$ to correct the volatility measure at that date. The dependent variable DT22 refers each day $t$ to the future volatility we have to predict, while the explanatory variable $Z_{t}$ is observed as of time $t$. The second is that the goodness of fit analysis in (15) is not an actual forecasting exercise, but a pure in-sample evaluation of the relationship between the two variables.

In this subsection we propose to perform a feasible correction of indicators for practitioners based on (15). For each trading day $t^{*}$ a two year rolling window (500 data) is used to obtain daily estimates $\hat{\beta}_{0, t^{*}}$ and $\hat{\beta}_{1, t^{*}}$ from (15) by considering data on $\left\{D T 22_{t}\right\}_{t=t^{*}-522}^{t^{*}-22}$ and data on $\left\{Z_{t}\right\}_{t=t^{*}-522}^{t^{*}-22}$, in both cases up to $t^{*}-22$, which is known $^{20}$ at time $t^{*}$. In fact, we are assuming that the past relationship between DT22 and $Z$ continues in the next month. Next, resulting daily estimates $\hat{\beta}_{0, t^{*}}$ and $\hat{\beta}_{1, t^{*}}$ are used to obtain the corrected volatility indicator at time $t^{*}\left(Z C_{t^{*}}\right)$ from (16). $Z C_{t^{*}}$ is considered the corrected volatility indicator, and it will be used as a predictor of IBEX-35 volatility from $t^{*}+1$ to $t^{*}+22$, as captured by $D T 22 t^{*}$.

$$
Z C_{t^{*}}=\hat{\beta}_{0, t^{*}}+\hat{\beta}_{1, t^{*}} Z_{t^{*}}
$$

We lose data as a consequence of this exercise. To illustrate this we present the Table 11, where we can advance the amount of information we finally use for conclusions about corrected indicators forecasting ability. In particular, we use the sample referred to in the last column to produce conclusions about the performance of each corrected indicator $Z_{t^{*}}$.

$\overline{20 \text { DT22 is only realized at time }} t+22$ (see (12)). 
Table 11 Sample available for each variable

\begin{tabular}{llll}
\hline & Z & ZC & Loss function \\
\hline VIBEX-NEW & $01 / 02 / 97$ to $03 / 30 / 07$ & $02 / 04 / 99$ to $03 / 30 / 07$ & $02 / 01 / 00$ to $03 / 30 / 07$ \\
IVC & $01 / 02 / 01$ to $11 / 18 / 05$ & $02 / 18 / 03$ to $11 / 18 / 05$ & $02 / 17 / 04$ to $11 / 18 / 05$ \\
BMK22 & $01 / 02 / 97$ to $03 / 30 / 07$ & $02 / 04 / 99$ to $03 / 30 / 07$ & $02 / 01 / 00$ to $03 / 30 / 07$ \\
IVG & $01 / 02 / 01$ to $03 / 30 / 07$ & $02 / 04 / 03$ to $03 / 30 / 07$ & $02 / 02 / 04$ to $03 / 30 / 07$ \\
\hline
\end{tabular}

Format: $\mathrm{mm} / \mathrm{dd} / \mathrm{yy}$

MAE: Original Volatility Indicators

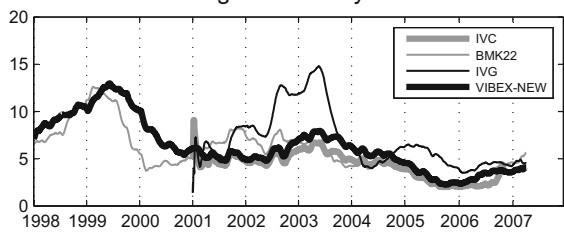

RMSE: Original Volatility Indicators

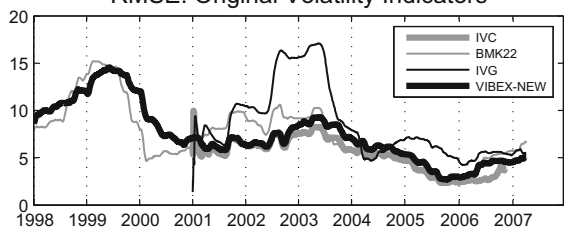

MAPE: Original Volatility Indicators

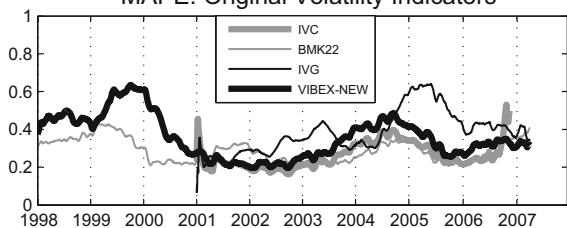

RMSPE: Original Volatility Indicators

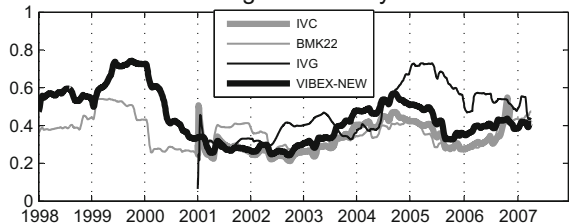

MAE: Corrected Volatility Indicators

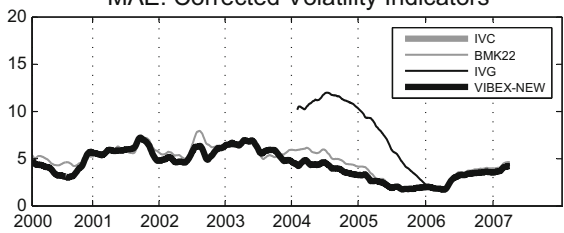

RMSE: Corrected Volatility Indicators

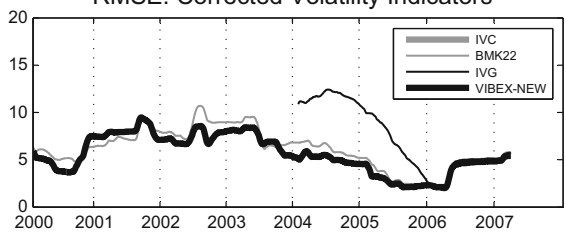

MAPE: Corrected Volatility Indicators

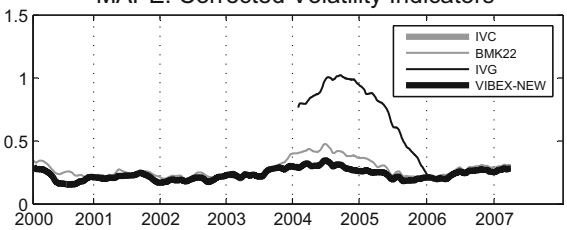

RMSPE: Corrected Volatility Indicators

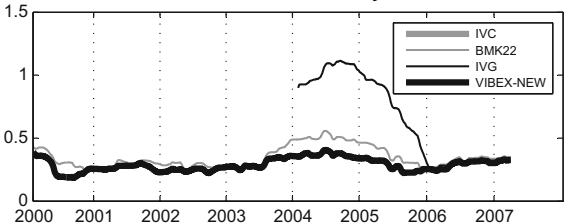

Fig. 7 MAE, RMSE, MAPE and RMSPE loss functions. Volatility indicators: original versus corrected. Each day loss function is computed by considering last 250 forecasting error

Figure 7, which contains eight figures, intends to illustrate the results. Figures on the left correspond to volatility indicators non-corrected and figures on the right correspond to the respective loss functions for volatility indicators corrected. The range in figures is between 2000 and 2007, the maximum we have for ZC.

The first thing to notice in the Figure is the ambiguous effect of correction in IVG and BMK22 forecasting ability. These seem to be better forecasters than the 
Table 12 Corrected volatility indicators

\begin{tabular}{|c|c|c|c|c|c|c|c|c|}
\hline & \multicolumn{4}{|l|}{ MAE } & \multicolumn{4}{|c|}{ RMSE } \\
\hline & IVC & BMK22 & IVG & VIBEX-NEW & IVC & BMK22 & IVG & VIBEX-NEW \\
\hline \multicolumn{9}{|c|}{ Whole sample } \\
\hline Mean & 3.20 & 4.81 & 6.39 & 4.35 & 4.03 & 6.13 & 7.32 & 5.61 \\
\hline Median & 3.32 & 5.17 & 4.47 & 4.37 & 4.58 & 6.29 & 5.73 & 5.34 \\
\hline$\sigma$ & 0.98 & 1.51 & 3.62 & 1.49 & 1.30 & 2.07 & 3.39 & 2.00 \\
\hline Min & 1.81 & 1.72 & 1.72 & 1.71 & 2.12 & 2.14 & 2.13 & 2.00 \\
\hline \multirow[t]{3}{*}{ Max } & 4.83 & 7.95 & 12.01 & 7.20 & 5.97 & 10.71 & 12.44 & 9.46 \\
\hline & \multicolumn{4}{|c|}{ MAE (mean) } & \multicolumn{4}{|c|}{ RMSE (mean) } \\
\hline & IVC & BMK22 & IVG & VIBEX-NEW & IVC & BMK22 & IVG & VIBEX-NEW \\
\hline \multicolumn{9}{|l|}{ Each year } \\
\hline 2000 & & 4.74 & & 3.99 & & 5.50 & & 4.90 \\
\hline 2001 & & 6.03 & & 5.95 & & 7.53 & & 8.04 \\
\hline 2002 & & 6.12 & & 5.35 & & 8.60 & & 7.39 \\
\hline 2003 & & 5.95 & & 6.04 & & 7.85 & & 7.25 \\
\hline 2004 & 4.08 & 5.35 & 11.13 & 4.14 & 5.18 & 6.23 & 11.67 & 5.14 \\
\hline 2005 & 2.36 & 2.58 & 6.22 & 2.28 & 2.92 & 3.33 & 7.08 & 2.85 \\
\hline 2006 & & 3.07 & 2.88 & 2.83 & & 4.06 & 4.08 & 3.82 \\
\hline $2007 *$ & & 4.30 & 3.93 & 3.89 & & 5.47 & 5.37 & 5.13 \\
\hline
\end{tabular}

Loss functions: MAE and RMSE. Original volatility indicators: mean, median, standard deviation, minimum and maximum are provided for the entire sample, as well as the mean value of loss functions in each year

* From January 2007 to March 2007

non-corrected in some periods, but worse in others. This is confirmed in Tables 12 and 13, where annual values for MAE, RMSE, MAPE and RMSPE are alternatively lower and higher than those in Tables 7 and 8 for IVG and BMK22. In any case, according to the Giacomini and White (2006) statistics in Table 14, IVC corrected indicator is much better forecaster (in both relative and nominal terms) than the BMK22 (notice that the statistics that relate both indicators are higher to 2.0 in absolute value, and negative, when $\varepsilon_{1}=$ IVC and $\varepsilon_{2}=\mathrm{BMK} 22$ in the tests).

On the contrary, corrected IVC and VIBEX-NEW seem to work, since loss functions take significant lower values than in the non-corrected version. In fact, relative annual forecasting error for VIBEX-NEW corrected is significantly less than the ones for VIBEX-NEW without correction (compare annual MAPE and RMSPE values in Tables 7 and 8 with the ones in Tables 12 and 13). The same happens for IVC. Therefore, it is possible to say that the forecasting ability for VIBEX-NEW corrected and IVC corrected seems to be higher than the non-corrected version and equivalent between them. This is confirmed by Giacomini and White (2006) statistics in Tables 14 and 15 . Table 14 reports the statistics for the common sample to pairwise indexes, and Table 15 reports similar statistics for the common sample to all the indexes. Indeed, we show that it is possible to correct VIBEX-NEW to be as good a forecaster as IVC, which we can confirm from same loss function values. Since the realized volatility 
Table 13 Corrected volatility indicators

\begin{tabular}{|c|c|c|c|c|c|c|c|c|}
\hline & \multicolumn{4}{|c|}{ MAPE } & \multicolumn{4}{|c|}{ RMSPE } \\
\hline & IVC & BMK22 & IVG & VIBEX-NEW & IVC & BMK22 & IVG & VIBEX-NEW \\
\hline \multicolumn{9}{|c|}{ Whole sample } \\
\hline Mean & 0.27 & 0.28 & 0.56 & 0.23 & 0.33 & 0.35 & 0.66 & 0.29 \\
\hline Median & 0.27 & 0.25 & 0.48 & 0.23 & 0.34 & 0.31 & 0.62 & 0.28 \\
\hline$\sigma$ & 0.04 & 0.07 & 0.31 & 0.04 & 0.05 & 0.08 & 0.33 & 0.05 \\
\hline Min & 0.19 & 0.19 & 0.18 & 0.15 & 0.23 & 0.23 & 0.24 & 0.18 \\
\hline \multirow[t]{3}{*}{ Max } & 0.34 & 0.48 & 1.02 & 0.35 & 0.41 & 0.56 & 1.11 & 0.41 \\
\hline & \multicolumn{4}{|c|}{ MAPE (mean) } & \multicolumn{4}{|c|}{ RMSPE (mean) } \\
\hline & IVC & BMK22 & IVG & VIBEX-NEW & IVC & BMK22 & IVG & VIBEX-NEW \\
\hline \multicolumn{9}{|l|}{ Each year } \\
\hline 2000 & & 0.27 & & 0.21 & & 0.33 & & 0.26 \\
\hline 2001 & & 0.24 & & 0.21 & & 0.29 & & 0.27 \\
\hline 2002 & & 0.22 & & 0.19 & & 0.28 & & 0.25 \\
\hline 2003 & & 0.25 & & 0.25 & & 0.33 & & 0.30 \\
\hline 2004 & 0.30 & 0.41 & 0.93 & 0.30 & 0.37 & 0.50 & 1.03 & 0.37 \\
\hline 2005 & 0.23 & 0.27 & 0.63 & 0.22 & 0.29 & 0.37 & 0.75 & 0.28 \\
\hline 2006 & & 0.26 & 0.24 & 0.24 & & 0.32 & 0.30 & 0.29 \\
\hline $2007 *$ & & 0.30 & 0.27 & 0.27 & & 0.35 & 0.32 & 0.32 \\
\hline
\end{tabular}

Loss functions: MAPE and RMSPE. Original volatility indicators: mean, median, standard deviation, minimum and maximum are provided for the entire sample, as well as the mean value of loss functions in each year

* From January 2007 to March 2007

Table 14 Giacomini and White (2006) test

\begin{tabular}{|c|c|c|c|c|c|c|c|}
\hline & \multicolumn{3}{|c|}{ Loss function: $\varepsilon_{t}^{2}$} & & \multicolumn{3}{|c|}{ Loss function: $\left|\varepsilon_{t}\right|$} \\
\hline & BMK22 & IVG & VIBEX-NEW & & BMK22 & IVG & VIBEX-NEW \\
\hline IVC & $-2.60^{\sharp}$ & $-4.08^{\sharp}$ & $0.51^{\sharp}$ & IVC & $-2.80^{\sharp}$ & $-4.51 \sharp$ & $-0.33^{\sharp}$ \\
\hline BMK22 & - & $-3.23^{b}$ & $1.03^{\dagger}$ & BMK22 & - & $-3.28^{b}$ & $1.41^{\dagger}$ \\
\hline \multirow[t]{3}{*}{ IVG } & - & - & $3.67^{b}$ & IVG & - & - & $3.81^{b}$ \\
\hline & \multicolumn{3}{|c|}{ Loss function: $\xi_{t}^{2}$} & & \multicolumn{3}{|c|}{ Loss function: $\left|\xi_{t}\right|$} \\
\hline & BMK22 & IVG & VIBEX-NEW & & BMK22 & IVG & VIBEX-NEW \\
\hline IVC & $-3.31^{\sharp}$ & $-3.82 \sharp$ & $0.73^{\sharp}$ & IVC & $-2.98^{\sharp}$ & $-4.36^{\sharp}$ & $0.09^{\#}$ \\
\hline BMK22 & - & $-3.15^{b}$ & $3.22^{\dagger}$ & BMK22 & - & $-3.23^{b}$ & $2.57^{\dagger}$ \\
\hline IVG & - & - & $3.35^{b}$ & IVG & - & - & $3.60^{b}$ \\
\hline
\end{tabular}

Unconditional predictive ability test. Square and absolute value loss functions. Common sample by pairs: $\sharp_{02} / \mathrm{Feb} / 2003-18 / \mathrm{Nov} / 2005,{ }^{b}$ 05/Feb/2003-30/Mar/2007, ${ }^{\dagger} 05 / \mathrm{Feb} / 1999-30 / \mathrm{Mar} / 2007$

is heteroscedastic (the higher the level the higher the dispersion), relative loss functions seem more useful to compare the forecasting availability of the indicators. To this respect, IVC and VIBEX-NEW corrected are better forecasters than IVG and 
Table 15 Giacomini and White (2006) test

\begin{tabular}{|c|c|c|c|c|c|c|c|}
\hline & \multicolumn{3}{|c|}{ Loss function: $\varepsilon_{t}^{2}$} & & \multicolumn{3}{|c|}{ Loss function: $\left|\varepsilon_{t}\right|$} \\
\hline & BMK22 & IVG & VIBEX-NEW & & BMK22 & IVG & VIBEX-NEW \\
\hline IVC & -2.60 & -4.08 & 0.51 & IVC & -2.80 & -4.51 & -0.33 \\
\hline BMK22 & - & -3.70 & 2.54 & BMK22 & - & -4.09 & 2.51 \\
\hline \multirow[t]{3}{*}{ IVG } & - & - & 4.12 & IVG & - & - & 4.47 \\
\hline & \multicolumn{3}{|c|}{ Loss function: $\xi_{t}^{2}$} & & \multicolumn{3}{|c|}{ Loss function: $\left|\xi_{t}\right|$} \\
\hline & BMK22 & IVG & VIBEX-NEW & & BMK22 & IVG & $\overline{\text { VIBEX-NEW }}$ \\
\hline$\overline{\text { IVC }}$ & -3.31 & -3.82 & 0.73 & IVC & -2.98 & -4.36 & 0.09 \\
\hline BMK22 & - & -3.64 & 3.29 & BMK22 & - & -4.07 & 2.65 \\
\hline IVG & - & - & 3.84 & IVG & - & - & 4.29 \\
\hline
\end{tabular}

Unconditional predictive ability test. Square and absolute value loss functions. Common sample: 02/Feb/2003-18/Nov/2005

BMK22, which can be confirmed in Fig. 7, and statistically by comparing annual loss function values in Tables 12, 13, 14 and 15. This is an even more interesting result because VIBEX-NEW is computed from public prices daily provided by the Clearing House at the end of each session.

It is interesting to note that, after the correction, the four volatility indicators converge at the end of the sample to a similar loss function, which does not happen in the non-corrected version. This means that their better performance coincides with a low sustainable volatility level in the market, when the DT22 dispersion is smaller, which explain the smaller forecasting error generated by indicators in the last part of the sample.

Summarizing, the positive relationship between the volatility indicators and future realized volatility in (15) allows a significant and feasible reduction in VIBEX-NEW and IVC forecast errors, often running between 2 and $5 \%$ points as an annual average, but not enough to eliminate them. Indeed, as a percentage of the level of volatility indicators, these errors seem too large to be of any help for risk management. The existence of the relationship between daily observations of IBEX-35 returns and changes in VIBEX-NEW leaves open the possibility of finding a way to exploit that relationship for volatility forecasting purposes. Therefore, our results also suggest that such a forecasting mechanism should be significantly more sophisticated than the one used in this section, an constitute a starting point to characterize the volatility risk premium in the Spanish Financial Market.

\section{Conclusion}

We have followed the same model-free methodology used by EUREX to estimate the German (VDAX-NEW) and Swiss (VSMI) volatility indices to construct a modelfree daily volatility index (VIBEX-NEW) for the Spanish market by using public data. The greater simplicity of this methodology compared to the model-based methodology makes it especially suitable to estimate a volatility index in a less than perfectly 
liquid market like the options market on the IBEX35 index. Moreover, since VIBEXNEW includes OTM call and put prices its information content is wider than the content in the model-based volatility index and its computation is more simple than the model-based which allows the valuation of derivatives on the volatility index. After constructing the VIBEX-NEW index, our purpose has been to analyze its information content regarding the evolution of the underlying market.

We have documented the negative, strong contemporaneous relationship of VIBEXNEW changes with IBEX returns in daily data. Such a relationship does not exist for alternative implicit or conditional volatility indicators, which shows the stronger ability of VIBEX-NEW to capture the risk sentiment in market participants. This result is even more interesting, because VIBEX-NEW has been computed by using public information provided at the end of the session by the Clearing House. It also suggests the possibility of using derivatives that might be issued on VIBEXNEW as the underlying asset, in order to improve risk management. The relationship between the volatility index and market returns is approximately symmetric on the daily volatility change sign and asymmetric on the stock index return sign, which makes VIBEX-NEW clearly a suitable volatility index for the Spanish financial markets.

We have also shown VIBEX-NEW is a biased predictor of future volatility, as is also the case for alternative volatility indicators. A regression designed to correct that bias provides a significant improvement in forecasting, although not by enough to justify its predictive ability for future realized volatility as a tool for risk management purposes. It is nevertheless quite amazing that a volatility index like VIBEX-NEW, which is not constructed with a forecasting goal in mind, could produce forecasts of future realized volatility at least as good as those emerging from historical volatility measures, and conditional volatility models from GARCH family. Finally, we also show that VIBEX-NEW can be modified in a feasible way to get a volatility forecaster as good as a volatility measure based on filtered intraday implied volatility. This result will be used in a future work to improve our knowledge on the volatility risk premium at Spanish Financial Markets.

In summary, our results are favorable to the view that the VIBEX-NEW volatility index is quite successful in capturing the current perception of risk by market participants. Additionally, the simplicity of calculation that arises from not using an option valuation model makes this index a good candidate to be used as the underlying asset for volatility derivatives, as has been done already in some countries with volatility indices calculated under the same methodology.

The turmoil in credit markets since the second semester of 2007 has not altered the high-frequency, close, negative relationship between changes in volatility and index returns. As might be expected, it has not led to any significant improvement in the ability of VIBEX-NEW to forecast future volatility, although it again performs comparably to historical volatility indicators, intraday implied volatility measures and conditional volatility models like GARCH(1,1). Additionally, the ability of VIBEXNEW to forecast future returns remains questionable. With no significant change in qualitative results, we believe it is better not to contaminate the statistical results with the addition of that period to our sample. A detailed analysis of the post-August 2007 events remains open as an extremely interesting question for further research. 
Open Access This article is distributed under the terms of the Creative Commons Attribution Noncommercial License which permits any noncommercial use, distribution, and reproduction in any medium, provided the original author(s) and source are credited.

\section{References}

Andersen TG, Bondarenko B (2007) Construction and interpretation of model-free implied volatility. CREATES Research Papers 2007-24, School of Economics and Management, University of Aarhus

Bali T, Weinbaum D (2007) A conditional extreme value volatility estimator based on high-frequency returns. J Econ Dyn Control 31(2):361-397

Becker R, Clements A, White S (2007) Does implied volatility provide any information beyond that captured in model-based volatility forecasts? J Banking Finance 31(8):2535-2549

Black F (1976) The pricing of commodity contracts. J Financial Econ 3(1-2):167-179

Black F, Scholes M (1973) The pricing of options and corporate liabilities. J Political Econ 81(2):637-654

Blair B, Poon SH, Taylor S (2001) Forecasting S\&P 100 volatility: the incremental information content of implied volatilities and high frequency index return. J Econ 105:5-26

Bollerslev T, Tauchen G, Zhou H (2009) Expected stock returns and variance risk premia. Rev Financial Stud 22(11):4463-4492

Box GEP, Jenkins GM, Reinsel GC (2008) Time series analysis, forecasting and control, 4th edn. Prentice Hall, Englewood Clifs

Britten-Jones M, Neuberger A (2000) Option prices, implied price processes and stochastic volatility. J Finance 22:621-651

Corrado CJ, Miller TW (2005) The forecast quality of CBOE implied volatility indexes. J Futures Markets 25(4):339-373

Demeterfi K, Derman E, Kamal M, Zou J (1999) More than you ever wanted to know about volatility swap. Goldman Sachs Quantitative Strategies Research Notes

Deutsche Borse (2007) Guide to the volatility indices of Deutsche Borse. Version 2.0. In: Nelken I (ed) Volatility as an asset class. Risk Books, London

Diebold F, Mariano R (1995) Comparing predictive accuracy. J Bus Econ Stat 13(3):253-263

Engle R, Gallo G (2007) A multiple indicators model for volatility using intra-daily data. J Econ 131(1-2): 3-27

Figlewski S, Wang X (2000) Is the 'leverage effect' a leverage effect? Available at SSRN: http://ssrn.com/ abstract=256109. doi:10.2139/ssrn.256109

Fleming J, Ostdiek B, Whaley R (1995) Predicting stock market volatility: a new measure. J Futures Mark 15(3):265-302

Giacomini R, White H (2006) Tests of conditional predictive ability. Econometrica 74(6):1545-1578

Giner J, Morini S (2004) El índice VIX para la predicción de volatilidad: un estudio internacional. Working paper 2004-10. Departamento de Economía Financiera y Contabilidad. Universidad de La Laguna

Giot P (2005) Relationships between implied volatility indices and stock index returns. J Portfolio Manag 31:92-100

Giot P, Laurent S (2007) The information content of implied volatility in light of the jump/continuous decomposition of realized volatility. J Futures Markets 27(4):337-359

Gonzalez-Perez M, Novales A (2009) Are volatility indices in international stock markets forward looking? Revista Real Academia de Ciencias Serie A Matematica Aplicada/Appl Math 103(2):339-352

Hibbert A, Daigler R, Dupoyet B (2008) A behavioral explanation for the negative asymmetric returnvolatility relation. J Banking Finance 32(2):2254-2266

Jiang G, Tian Y (2007) Extracting model-free volatility from option prices: an examination of the VIX index. J Deriv 14(3):1-26

Noh J, Engle R, Kane A (1994) Forecasting volatility and option prices of the S\&P 500 index. J Deriv 2(1):17-30

Poon SH, Granger C (2008) Forecasting volatility in financial markets: a review. J Econ Lit 41:478-539

Simon D (2003) The NASDAQ volatility index during and after the bubble. J Deriv Winter:9-24

Skiadopoulos G (2004) The Greek implied volatility index: construction and properties. Appl Financial Econ 14:1187-1196

Whaley RE (2000) The investor fear gauge. J Portfolio Manag 26(3):12-17

Whaley RE (2009) Understanding VIX. J Portfolio Manag 35(3):98-105 